Article

\title{
Effective Inhibition of Carbon Steel Corrosion by Waterborne Polyurethane Based on N-tert-Butyl Diethanolamine in 2M HCl: Experimental and Computational Findings
}

Yulia F. Zaripova ${ }^{1}$, Sherzod Razhabov ${ }^{2}$, Roman S. Pavelyev ${ }^{1}$ D , Svetlana S. Vinogradova ${ }^{2, *}$, Renat R. Nazmutdinov ${ }^{2}$, Iskander R. Vakhitov ${ }^{3}$ and Mikhail A. Varfolomeev ${ }^{1, * \mathbb{D}}$

1 Department of Petroleum Engineering, Kazan Federal University, Kremlevskaya Str. 18, 420008 Kazan, Russia; yu-ya98@yandex.ru (Y.F.Z.); rpavelyev@gmail.com (R.S.P.)

2 Department of Electrochemical Engineering, Kazan National Research Technological University, Karl Marx Str. 68, 420015 Kazan, Russia; sherzodrazhabov@mail.ru (S.R.); nazmutdi@mail.ru (R.R.N.)

3 Department of Physics, Kazan Federal University, Kremlevskaya Str. 18, 420008 Kazan, Russia; iskvakhitov@gmail.com

* Correspondence: vsvet@kstu.ru (S.S.V.); vma.ksu@gmail.com (M.A.V.)

Citation: Zaripova, Y.F.; Razhabov, S.; Pavelyev, R.S.; Vinogradova, S.S.; Nazmutdinov, R.R.; Vakhitov, I.R.; Varfolomeev, M.A. Effective Inhibition of Carbon Steel Corrosion by Waterborne Polyurethane Based on N-tert-Butyl Diethanolamine in $2 \mathrm{M} \mathrm{HCl}$ : Experimental and Computational Findings. Energies 2022, 15, 1939. https://doi.org/ 10.3390/en15051939

Academic Editor: Jude O. Iroh

Received: 18 January 2022

Accepted: 1 March 2022

Published: 7 March 2022

Publisher's Note: MDPI stays neutral with regard to jurisdictional claims in published maps and institutional affiliations.

Copyright: (C) 2022 by the authors. Licensee MDPI, Basel, Switzerland. This article is an open access article distributed under the terms and conditions of the Creative Commons Attribution (CC BY) license (https:// creativecommons.org/licenses/by/ $4.0 /)$.

\begin{abstract}
The efficiency of corrosion inhibition for waterborne polyurethane based on N-tert-butyl diethanolamine $(t B-W P U)$ is investigated using different techniques. Corrosion weight loss, open circuit potential experiments, electrochemical impedance spectroscopy, and potentiodynamic polarization measurements show that both a commercial reagent and a polyurethane-based inhibitor prevent corrosion at increasing temperature to $50{ }^{\circ} \mathrm{C}$. At $75^{\circ} \mathrm{C}$, the activity of both reagents is reduced. In stirring conditions, the effectiveness of acid corrosion inhibition $\left(25^{\circ} \mathrm{C}, 500 \mathrm{ppm}\right)$ drops abruptly from $89.5 \%$ to $60.7 \%$, which is related presumably to the complexity of binding the polymer molecules to the metal surface. As follows from thermodynamic calculations, the adsorption of $t B-W P U$ on the metal surface in $2 \mathrm{M} \mathrm{HCl}$ can be treated as a physisorption. Model quantum-chemical calculations support the experimental studies and elucidate the nature of steel surface-inhibitor molecule chemical bond, which is realized mainly by carboxyl and amino groups. It is concluded that WPUs can be considered as a perspective alternative to commercial oilfield reagents due to their versatility.
\end{abstract}

Keywords: corrosion inhibition; acid corrosion; dual-functional inhibitors; carbon steel; waterborne polyurethanes; density functional theory

\section{Introduction}

Corrosion is a problem that may have severe economic effects [1]. Carbon steel (CS) is a widely used alloy, due to its affordable cost and high strength characteristics. Various products are made from steels consisting of iron and carbon and a minimum of other impurities [2]. However, in many manufacturing processes, CS suffers from pronounced uneven or local electrochemical corrosion [3]. At the same time, acidification, including acid injection into a well or a geological formation producing oil and/or gas, is an important method of enhancing oil recovery [4].

Designing efficient inhibitors to prevent acid corrosion is a priority task for the industry. Various corrosion inhibitors (CIs) are widely used to solve corrosion problems in this procedure [5-8]. It is a relatively profitable and efficient technique. A key factor of preventing corrosion is the ability of inhibitor molecules to adsorb on the metal surface, creating a protective film. Therefore, it is important to select an appropriate inhibitor for a particular metal [4]. The presence of $\pi$-electrons, heteroatoms (such as sulfur, nitrogen, or oxygen), and polar/aromatic functional groups in the compound structure usually leads to increasing the inhibitory activity. Imidazolines, phosphate esters, and quaternary ammonium surfactants are the most prevalent flow line CIs [4,9-12]. 
Inhibitors are classified by their mechanisms, i.e., cathode, anode, or mixed; their chemical composition, i.e., organic, mineral, or volatile; or application, i.e., for acidic, neutral, or alkaline services [13]. There are two inhibiting schemes: Changing the energy that activates the corrosion process and reducing the surface area exposed to corrosion.

Currently, more attention is being paid to environmentally friendly and biodegradable inhibitors [14-18]. In some countries, environmental protection organizations have introduced strict rules and regulations on bioaccumulation, biodegradability, and toxicity [19]. PARCOM (PARis COMmission) has established standard tests that cover these three aspects [20].

Gas hydrates are also discussed as one of the challenges the oil and gas industry faces today $[21,22]$. Different problems require different reagents to solve them; however, many simultaneously used chemicals lead to an increase in the cost of storage, transportation, and regeneration. In addition, it has been shown that inhibitors of different types, such as those inhibiting hydrates and those inhibiting corrosion, may suppress each other's activity $[23,24]$. Therefore, a challenge is to create multifunctional reagents that would be commercially available and environmentally friendly, on the one hand, and could efficiently inhibit several processes simultaneously, on the other hand. Earlier, our team developed a new, promising class of hydrate formation inhibitors based on water-soluble polyurethanes [25-28]. These compounds have manifested significant benefits in inhibiting hydrate formation, as compared to commercial reagents, such as Luvicap EG and Luvicap $55 \mathrm{~W}$. This class of compounds was chosen due to their ability to synthesize molecules with the desired properties and under mild conditions.

This paper is the first to describe the detailed study of the anticorrosive effect of this type of polymers, i.e., complex inhibitors that inhibit both corrosion and hydrate formation. Inhibitory behavior of waterborne polyurethane based on N-tert-butyl diethanolamine was evaluated for CS in $2 \mathrm{M} \mathrm{HCl}$ solution at 298-348 K using weight loss measurements, open circuit potential (OCP) values, potentiodynamic polarization (PDP) curves, electrochemical impedance spectroscopy (EIS), and profilometry. A correlation between molecular structure and inhibition properties was explored using model quantum-chemical calculations at the density functional theory level. The polymer under study inhibits quite efficiently both acid corrosion of steel 3 at $25^{\circ} \mathrm{C}$ and the nucleation/growth of gas hydrates (comparable to commercial inhibitors). Thus, this reagent shows a complex action, which is promising for oilfield chemistry [24].

\section{Experiment}

\subsection{Materials}

For all the experiments, deionized water was obtained via the Arium Mini Plus Ultrapure Water System by Sartorius, Germany $\left(18.20 \mathrm{M} \Omega \mathrm{cm}\right.$ at $\left.25^{\circ} \mathrm{C}\right)$. Hydrochloric acid was used to study acid corrosion (Acros Organics, Belgium). Commercial amine-type reagent, Armohib CI-28 by AkzoNobel, The Netherlands, was used as a reference inhibitor.

\subsection{Synthesizing Waterborne Polyurethane}

To study anticorrosive activity, waterborne polyurethane was obtained by the method described in [28]. Briefly, polyethylene glycol (PEG 400) and dimethylol propionic acid (DMPA) were mixed at $70^{\circ} \mathrm{C}$ for $30 \mathrm{~min}$ to obtain a homogeneous solution. Afterwards, isophoron diisocyanate (IP) was added to the reaction mixture, and the reaction was continued at $85{ }^{\circ} \mathrm{C}$ for two hours, tetrahydrofuran (THF) being added to decrease the viscosity of the reaction mixture. After $2 \mathrm{~h}$, N-butyl diethanolamine was added, and the reaction run at $85{ }^{\circ} \mathrm{C}$ for 5 more hours. At the end of the reaction, the solution was cooled down to $25^{\circ} \mathrm{C}$, and triethylamine (TEA 1.2 equivalents of DMPA) was added to neutralize the solution. The polymer obtained was dried on a rotary evaporator and dissolved in demineralized water to prepare the final solution. Figure 1 shows the structure of the resulting compound. 


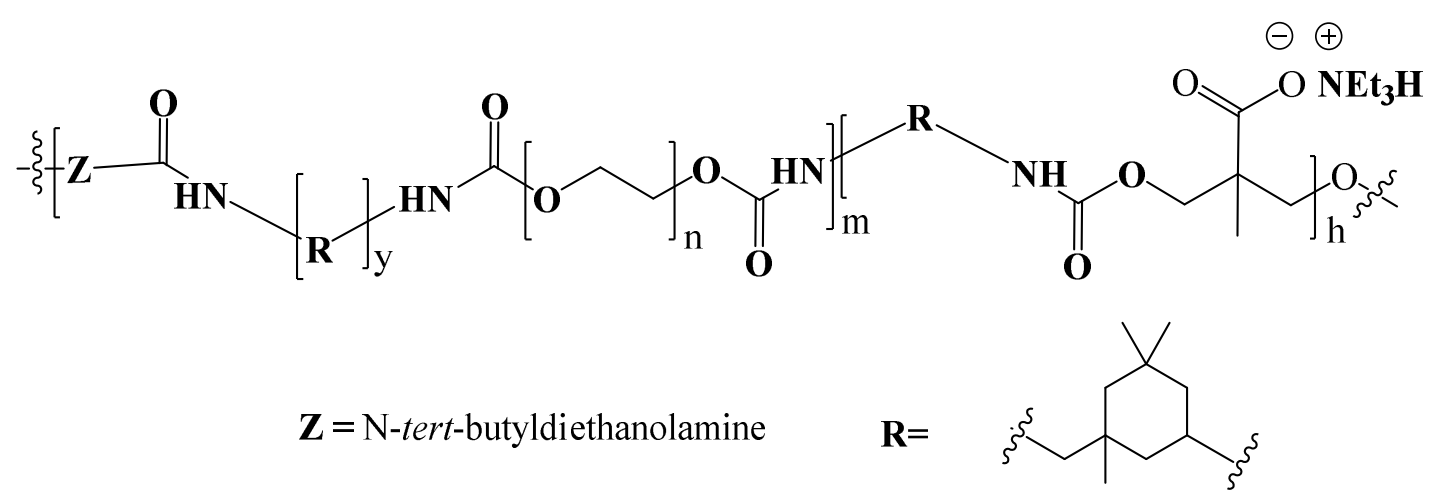

Figure 1. Structure of the polyurethane based on N-butyl diethanolamine.

\subsection{Corrosion Weight Loss Experiments}

Carbon steel coupons (sized $2.54 \mathrm{~cm} \times 5.08 \mathrm{~cm} \times 0.16 \mathrm{~cm}$; composition $(\mathrm{wt} \%): 0.24$ of $\mathrm{C} ; 0.37$ of $\mathrm{Si} ; 0.65$ of $\mathrm{Mn} ; 0.25$ of $\mathrm{Cu} ; 0.25$ of $\mathrm{Ni} ; 0.08$ of As; 0.045 of $\mathrm{S} ; 0.035$ of $\mathrm{P}$, and 98.08 of $\mathrm{Fe}$ ) were cleaned with distilled water and ethanol. Using emery papers (grain size 800, 1000, and 1200), the CS surface was polished and then cleaned again. A high-resolution (0.00001 g, Sartorius Cubis) analytical balance was used for weighing the initial $\left(\mathrm{W}_{0}\right)$ and final $\left(\mathrm{W}_{24}\right)$ weights of CS coupons. Experiments were carried out at 25,50 , and $75{ }^{\circ} \mathrm{C}$ in the $2 \mathrm{M} \mathrm{HCl}$ solution at different reagent concentrations in open glass beakers for $24 \mathrm{~h}$. The steel coupons were then triple washed with ethanol and distilled water and weighed again. To achieve reproducibility of the results, the experiment was conducted thrice. Corrosion rate $(\mathrm{mm} / \mathrm{y})$, inhibition efficiency $(\% I E w)$, and surface coverage $(\theta)$ were calculated as follows [29]:

$$
\begin{aligned}
C R & =\frac{8.76 \times 10^{4} \times \Delta m}{s \times t \times \rho} \\
\% I E w & =\frac{C R_{0}-C R_{i n h}}{C R_{0}} \times 100 \%
\end{aligned}
$$

where $\Delta m(\mathrm{~g}), s\left(\mathrm{~cm}^{2}\right), t(\mathrm{~h})$, and $\rho\left(\mathrm{g} \mathrm{cm}^{-3}\right)$ are the average CS weight loss value, the total CS surface area, the corrosion time, and the CS density, respectively.

\subsection{Electrochemical Measurements}

Samples in form of rectangular steel plates sized $5 \mathrm{~cm}$ (length) $\times 2 \mathrm{~cm}$ (width) $\times 1 \mathrm{~mm}$ (thickness) were used as electrodes. At least five samples were taken for the study from one batch of steel. Solution: $2 \mathrm{M} \mathrm{HCl}$ with/without adding an inhibitor. Sample preparation, electrochemical measurements of the open circuit potential (EOCP), computation of corrosion potential $\left(E_{\text {corr }}\right)$, values of the Tafel equation parameters $\left(\beta_{\mathrm{a}}, \beta_{\mathrm{k}}\right)$, and corrosion rate $\left(\mathrm{j}_{\text {corr }}\right)$; and calculation of the inhibition efficiency $(\% I E)$ were carried out according to conventional methods published earlier [28]. To determine the Tafel constants, a stepped potential sweep with a sweep rate of $1 \mathrm{mV} / \mathrm{s}$ was used. The values of the potential range of the working electrode were set from $-250 \mathrm{mV}$ to $250 \mathrm{mV}$ of the OCP value. To maintain a constant temperature in the solution, a thermostatic bath was used. Stirring was carried out using a UED-20 magnetic stirrer with stirring speed of $100 \mathrm{rpm}$.

Impedance studies were carried out within potential values ranging from 0.1 to $0.3 \mathrm{~V}$, imposing a sinusoidal signal with the amplitude of $5 \mathrm{mV}$ (potential step of $10 \mathrm{mV}$, frequency range 100,000-0.1 Hz). The ZIVE SP2 Electrochemical Workstation software includes the Zman software package with ready-made methods for corrosion research [30]. This package was used to select an optimal electrical equivalent circuit for describing the electrochemical behavior of the samples under study, to calculate its parameters, and to compare the calculated data and the experimental findings. Parameter $\chi^{2}$ calculated by ZMan was used as a criterion for evaluating circuits for their suitability for modeling experimental impedance spectra. The equivalent scheme was considered to satisfy $x^{2}<10^{-3}$. Upon 
completion of the calculations, the adequacy of the impedance data was assessed by comparing them with the results of the Nyquist and Bode diagrams.

\subsection{Quantum-Chemical Calculations}

Since a real inhibitor molecule in anionic form is quite complicated for atomistic modeling, it was replaced with a simpler model anion (see Figure 2a), hereinafter to be abbreviated as $\mathrm{mim}^{-}$(model inhibitor molecule). Density Functional Theory (DFT) calculations of $\mathrm{mim}^{-}$and the cation (triethyl ammonium, $\mathrm{NEt}_{3} \mathrm{H}^{+}$, see Figure $2 \mathrm{~b}$ ) in bulk were performed using the B3LYP hybrid functional as implemented into the Gaussian 16 software package [31]. For the O, N, C, and H atoms, the standard 6-31g (d, p) basis was used. Molecular geometry was optimized without symmetry constraints. Solvent effects were addressed implicitly within the Polarizable Continuum Model (PCM) [28] using values of 78 and 1.8 for static and optical dielectric constants, respectively. Geometry of molecules and orbitals was visualized by the Chemcraft program [32].

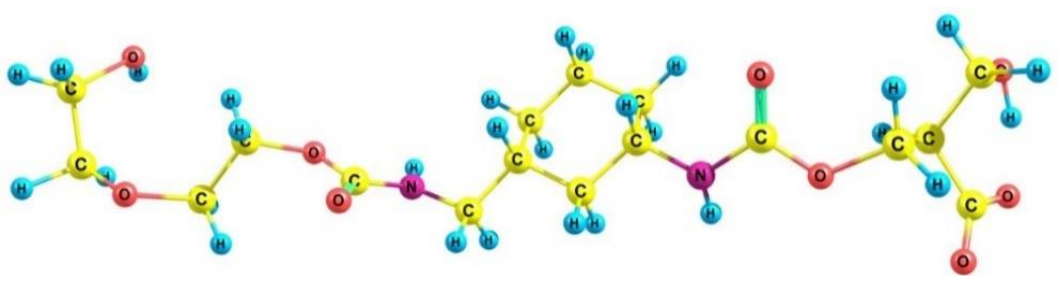

(a)

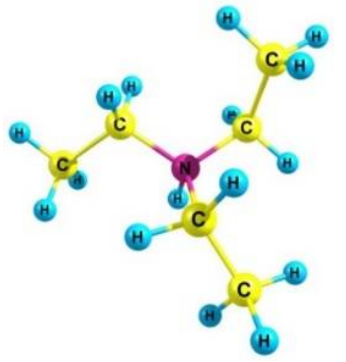

(b)

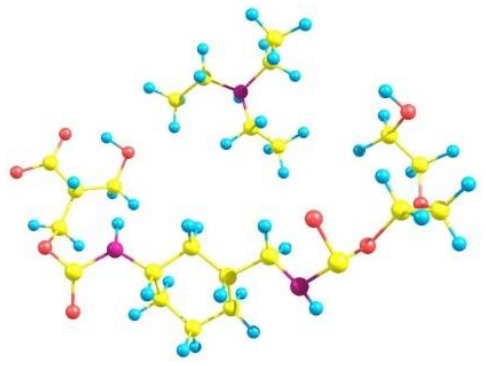

(c)

Figure 2. (a) Optimized geometry of the model inhibitor (anion); (b) triethyl ammonium (cation); (c) contact anion-cation ionic pair.

Adsorption of the $\mathrm{mim}^{-}$anion at an iron electrode surface was treated in terms of periodic DFT calculations. The metal surface was represented by its low-index face (100) with an assumed bcc lattice for $\alpha$-Fe. DFT calculations were performed using the SIESTA program suite $[14,33]$. The $\mathrm{Fe}(100)$ surface was modeled by repeated supercells consisting of two slabs $(36+36)$ with a vacuum thickness of $2.5 \mathrm{~nm}$ (see Figure 2); and the Fe(110) surface was modeled in [34] in a similar way. Since a unit cell in periodic calculations must be neutral, it additionally includes the $\mathrm{NEt}_{3} \mathrm{H}^{+}$cation that is not directly bound to the metal surface. Molecules adsorbed were assumed to form a monolayer of the $\mathrm{c}(2 \times 2)$ structure, albeit the lattice symmetry is not crucial for our modeling. Neither solvent environment nor the electrode charge was considered. GGA (Generalized Gradient Approximation) functional in the Perdew, Burke, and Ernzerhof (PBE) version [35] was combined with a numerical basis set of DZ quality and the Troullier-Martins norm-conserving soft ECP (Effective Core Potential) [36]. The Brillouin zone integration was accomplished using a $2 \times 2 \times 1 k$-point Monkhorst-Pack grid with respect to the surface unit cell. Energy of $200 \mathrm{Ry}$ was taken as the cutoff in all calculations. Position of the Fe atoms was fixed, while we allowed the atoms of adsorbed molecules to relax. Adsorbate geometry was optimized until the residual force on each atom was below $0.01 \mathrm{eV} / \AA$. Broyden mixing and FermiDirac smearing with the electronic temperature set at $300 \mathrm{~K}$ were applied to accelerate the SCF (Self-Consistent Field) convergence. Spin polarization and dipole correction were addressed in all calculations. 


\subsection{Studying Surface Morphology}

For studying the surface roughness of metal coupons, the DektakXT profilometer manufactured by Bruker, Germany (stylus radius: $2 \mu \mathrm{m}$ ), was used with an accuracy of at worst $10 \mathrm{~nm}$. Surface mapping was used to display the topological 3D images of the coupons. 3D maps of the surface morphology were analyzed with a scanning area of $1000 \times 1000 \mu \mathrm{m}$ (trace resolution $0.167 \mu \mathrm{m} / \mathrm{pt}$, map resolution $40 \mu \mathrm{m} /$ trace).

\section{Results and Discussion}

\subsection{Weight Loss Experiments}

Corrosion inhibition activity was initially evaluated by the weight loss method because it is considered an easy method for finding out how inhibitor concentration affects its efficiency. The measured results are reproducible in triplicate with standard deviations ranging from 0.00035 to $0.0004 \mathrm{~g}$. Sample $t B$ - $W P U$ in gravimetric experiments demonstrated the $90.6 \%$ inhibition efficiency at $100 \mathrm{ppm}$ [28]. A decision was taken to check whether the compound above could prevent corrosion at 50 and $75^{\circ} \mathrm{C}$. Findings of weight loss studies at higher temperatures are shown below.

It is clear (Table 1 and Figure 3) that at $25^{\circ} \mathrm{C}$, both Armohib CI-28 and $t B-W P U$ inhibit corrosion efficiently. At $75{ }^{\circ} \mathrm{C}$, the effect of both reagents becomes lower. $t B$-WPU reduces acid corrosion by coating the CS surface, i.e., surface coating is the most important factor in corrosion prevention efficacy.

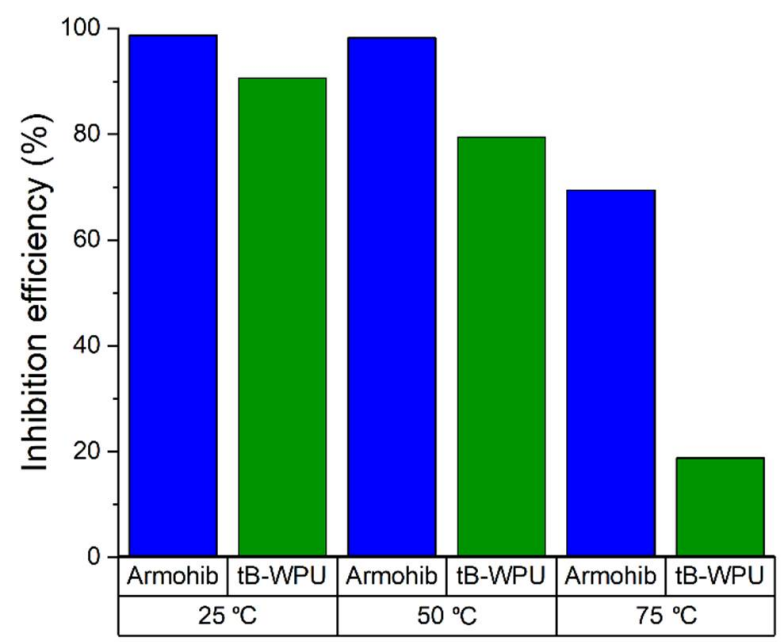

Figure 3. Inhibition efficiency measurement data at different temperatures.

Table 1. Weight loss measurement data with and without inhibitors at different temperatures.

\begin{tabular}{cccc}
\hline Sample & Concentration & Corrosion Rate (mm/Year) & \%IEw \\
\hline \multicolumn{5}{c}{$25^{\circ} \mathrm{C}$} \\
\hline W/o inhibitor & - & 9.19 & - \\
$t B-W P U$ & $100 \mathrm{ppm}$ & 0.41 & 90.6 \\
Armohib CI-28 & $100 \mathrm{ppm}$ & 0.058 & 98.7 \\
\hline \multicolumn{5}{c}{$50^{\circ} \mathrm{C}$} \\
W/o inhibitor & - & 61.85 & - \\
$t B-W P U$ & $100 \mathrm{ppm}$ & 12.7 & 79.47 \\
Armohib CI-28 & $100 \mathrm{ppm}$ & 1.09 & \\
\hline & & & - \\
\hline W/o inhibitor & - & 91.23 \\
$t B-W P U$ & $100 \mathrm{ppm}$ & 74.07 & 18.78 \\
Armohib CI-28 & $100 \mathrm{ppm}$ & 27.84 & 69.47 \\
\hline
\end{tabular}




\subsection{Electrochemical Measurements}

\subsubsection{Open Circuit Potential (OCP) Experiments}

OCP was recorded at various concentrations of $t B-W P U$. Registration time of $30 \mathrm{~min}$ was sufficient to stabilize the OCP. Changes in OCP at different temperatures were less than $25 \mathrm{mV}$ in blank and $t B-W P U$ solutions.

An increase in the temperature of the solution showed that at $25{ }^{\circ} \mathrm{C}$, the values of the OCP: $-511.5,-464.2,-462.6$, and $-460.8 \mathrm{mV}$ (blank, 50, 100, $500 \mathrm{ppm}$ of $t B-W P U$ ) (Figure 4a); at $75^{\circ} \mathrm{C}-523.4,-513.3,-518.2$, and $-519.7 \mathrm{mV}$ (blank, 50, 100, $500 \mathrm{ppm}$ of $t B-W P U$ ) (Figure 4e). The maximum difference in OCP (blank and $t B-W P U$ ) was $50.7 \mathrm{mV}$ at $25^{\circ} \mathrm{C}$ and $10.1 \mathrm{mV}$ at $75^{\circ} \mathrm{C}$.

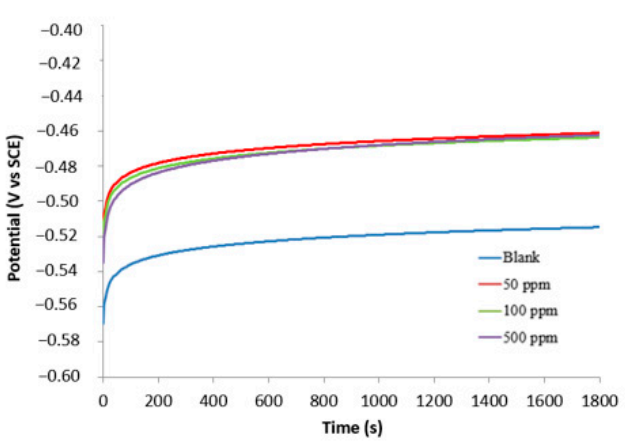

(a)

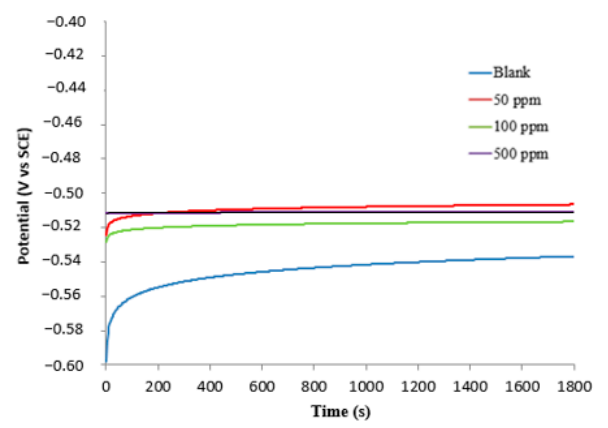

(c)

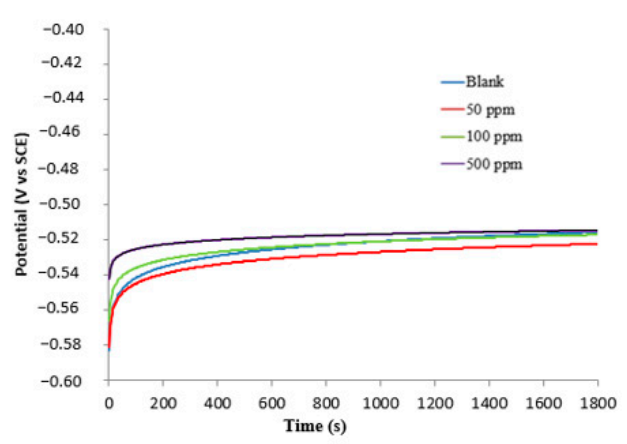

(e)

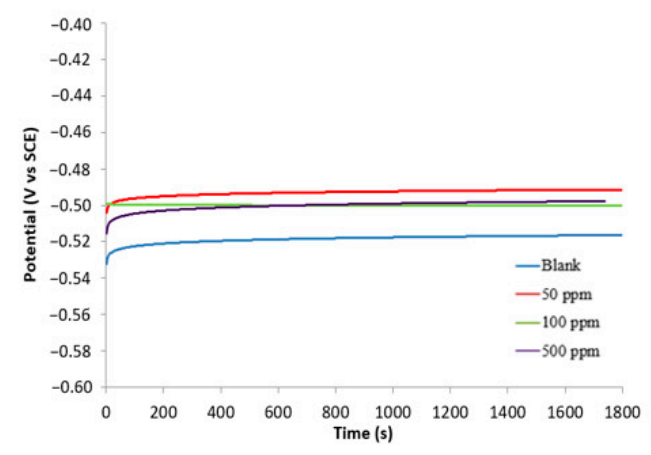

(b)

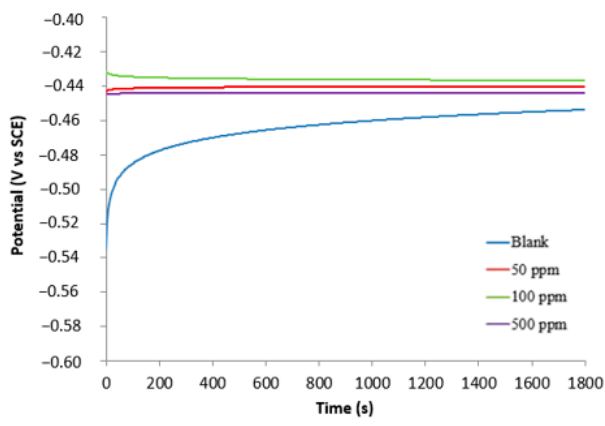

(d)

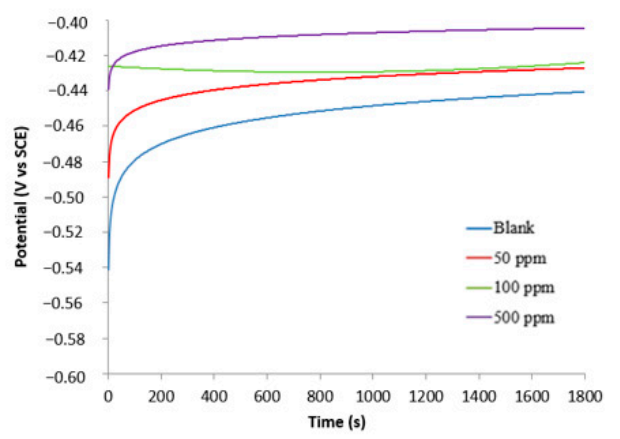

(f)

Figure 4. Time evolution of OCP measured for $\mathrm{CS}$ in $2 \mathrm{M} \mathrm{HCl}$ in the absence and presence of different concentrations of $t B-W P U$ at different temperatures $(\mathbf{a}, \mathbf{c}, \mathbf{e}) \mathrm{w} / \mathrm{o}$ stirring; $(\mathbf{b}, \mathbf{d}, \mathbf{f})$ with stirring; (a,b) $25{ }^{\circ} \mathrm{C} ;(\mathbf{c}, \mathbf{d}) 50^{\circ} \mathrm{C} ;(\mathbf{e}, \mathbf{f}) 75^{\circ} \mathrm{C}$.

If the displacement in $E_{\text {corr }}$ is $>85 \mathrm{mV}$ with respect to the $E_{\text {corr }}$ of blank solution, the inhibitor can be seen as an anodic or cathodic type inhibitor, and if the displacement in $\mathrm{E}_{\mathrm{corr}}$ is $<85 \mathrm{mV}$, implying that $t B-W P U$ acts as a mixed type corrosion inhibitor [37]. 
$T B-W P U$ reduces the anodic dissolution of CS and suppresses the reaction of cathodic hydrogen release.

Stirring the solution resulted in the OCP potential shifting in a positive direction for all the temperatures studied. This is due to an increase in the rate of adsorption of the inhibitor on the CS surface. OCP values for $500 \mathrm{ppm}$ of $t B-W P U \mathrm{w} / \mathrm{o}$ stirring and with stirring are -460.8 and $-426.8 \mathrm{mV}$ at $20^{\circ} \mathrm{C},-513.3$ and $-505.3 \mathrm{mV}$ at $75{ }^{\circ} \mathrm{C}$, respectively.

\subsubsection{Potentiodynamic Polarization (PDP) Measurements}

Electrochemical kinetic parameters, i.e., corrosion potential ( $\left.\mathrm{E}_{\mathrm{corr}}\right)$, corrosion current density ( $\left.\mathrm{i}_{\mathrm{corr}}\right)$, and slopes of the cathode and anode branches $\left(\beta_{\mathrm{c}}\right.$ and $\left.\beta_{\mathrm{a}}\right)$ were obtained based on the analysis of polarization curves in various conditions (Table 2).

Table 2. Kinetic parameters for corrosion process in the presence of $t B-W P U$ and Armohib CI-28 inhibitors at different temperatures.

\begin{tabular}{|c|c|c|c|c|c|c|}
\hline Inhibitor Concentration & $\mathrm{E}_{\mathrm{ocp}}(\mathrm{mV}$ sCE $)$ & $\beta_{\mathrm{a}}(\mathrm{V} / \mathrm{div})$ & $\beta_{c}(\mathrm{~V} / \mathrm{div})$ & $\mathrm{E}_{\text {corr }}(\mathrm{mV})$ & $I_{\text {corr }}\left(\mathbf{m A} \cdot \mathrm{cm}^{-2}\right)$ & $\% I E$ \\
\hline \multicolumn{7}{|c|}{$25^{\circ} \mathrm{C}$ w/o stirring $(t B-W P U)$} \\
\hline 500 ppm & -460.8 & 0.090 & 0.205 & -459.099 & 0.036 & 89.5 \\
\hline $100 \mathrm{ppm}$ & -462.6 & 0.138 & 0.179 & -497.252 & 0.044 & 87.2 \\
\hline 50 ppm & -464.2 & 0.090 & 0.154 & -486.421 & 0.097 & 71.9 \\
\hline 0 ppm & -511.5 & 0.118 & 0.192 & -504.618 & 0.347 & - \\
\hline \multicolumn{7}{|c|}{$25^{\circ} \mathrm{C}$ w/o stirring (Armohib CI-28) } \\
\hline 500 ppm & -483.1 & 0.09 & 0.208 & -478.083 & 0.014 & 96.0 \\
\hline 100 ppm & -484.1 & 0.095 & 0.204 & -481.736 & 0.024 & 93.2 \\
\hline 50 ppm & -491.2 & 0.091 & 0.10 & -484.843 & 0.029 & 91.7 \\
\hline 0 ppm & -511.5 & 0.118 & 0.192 & -504.618 & 0.347 & - \\
\hline \multicolumn{7}{|c|}{$25{ }^{\circ} \mathrm{C}$ with stirring $(t B-W P U)$} \\
\hline $500 \mathrm{ppm}$ & -426.8 & 0.067 & 0.139 & -478.309 & 0.062 & 60.7 \\
\hline $100 \mathrm{ppm}$ & -449.9 & 0.075 & 0.188 & -481.106 & 0.068 & 57.1 \\
\hline 50 ppm & -492.9 & 0.079 & 0.231 & -486.537 & 0.096 & 39.7 \\
\hline 0 ppm & -516.2 & 0.037 & 0.177 & -528.6 & 0.161 & - \\
\hline \multicolumn{7}{|c|}{$25^{\circ} \mathrm{C}$ with stirring (Armohib CI-28) } \\
\hline 500 ppm & -401.6 & 0.080 & 0.123 & -392.629 & 0.037 & 71.5 \\
\hline 100 ppm & -405.8 & 0.099 & 0.183 & -398.484 & 0.053 & 59.2 \\
\hline 50 ppm & -413.8 & 0.117 & 0.274 & -405.013 & 0.067 & 48.5 \\
\hline 0 ppm & -516.1 & 0.068 & 0.177 & -494.276 & 0.130 & - \\
\hline \multicolumn{7}{|c|}{$50{ }^{\circ} \mathrm{C}$ w/o stirring $(t B-W P U)$} \\
\hline 500 ppm & -517.6 & 0.078 & 0.153 & -509.5 & 0.219 & 83.2 \\
\hline 100 ppm & -522.2 & 0.08 & 0.151 & -514.6 & 0.247 & 81.0 \\
\hline 50 ppm & -528.1 & 0.063 & 0.083 & -517.064 & 0.282 & 74.4 \\
\hline 0 ppm & -536.2 & 0.071 & 0.135 & -525.7 & 1.30 & - \\
\hline \multicolumn{7}{|c|}{$50{ }^{\circ} \mathrm{C}$ with stirring $(t B-W P U)$} \\
\hline 500 ppm & -437.3 & 0.045 & 0.071 & -399.706 & 0.113 & 60.4 \\
\hline $100 \mathrm{ppm}$ & -441.6 & 0.044 & 0.077 & -411.709 & 0.169 & 40.7 \\
\hline 50 ppm & -443.4 & 0.048 & 0.101 & -417.126 & 0.200 & 29.7 \\
\hline 0 ppm & -450.4 & 0.047 & 0.208 & -423.885 & 0.285 & - \\
\hline \multicolumn{7}{|c|}{$75^{\circ} \mathrm{C}$ w/o stirring $(t B-W P U)$} \\
\hline 500 ppm & -513.3 & 0.097 & 0.254 & -494.281 & 1.301 & 49.6 \\
\hline $100 \mathrm{ppm}$ & -518.2 & 0.056 & 0.094 & -502.227 & 1.702 & 33.9 \\
\hline 50 ppm & -519.7 & 0.062 & 0.088 & -508.754 & 1.860 & 27.7 \\
\hline 0 ppm & -523.4 & 0.062 & 0.093 & -511.388 & 2.600 & - \\
\hline \multicolumn{7}{|c|}{$75^{\circ} \mathrm{C}$ with stirring $(t B-W P U)$} \\
\hline 500 ppm & -505.3 & 0.042 & 0.075 & -384.638 & 0.537 & 56.1 \\
\hline $100 \mathrm{ppm}$ & -524.5 & 0.033 & 0.040 & -404.285 & 0.773 & 36.8 \\
\hline 50 ppm & -527.6 & 0.026 & 0.035 & -412.309 & 1.119 & 8.5 \\
\hline 0 ppm & -532.7 & 0.034 & 0.043 & -422.128 & 1.223 & - \\
\hline
\end{tabular}


Dynamic conditions significantly reduced the inhibition efficiency from $89.5 \%$ without stirring down to $60.7 \%$ with stirring $\left(25^{\circ} \mathrm{C}\right)$. It is known that when mixing the solution, the inhibitor film desorption from a steel surface increases. An increase in temperature to $75{ }^{\circ} \mathrm{C}$ negatively affected the inhibitory properties: $25^{\circ} \mathrm{C}(89.5 \%), 50{ }^{\circ} \mathrm{C}(83.2 \%), 75{ }^{\circ} \mathrm{C}(49.6 \%)$.

It is possible to classify an inhibitor by the value changes in the corrosion potential $\left(\mathrm{E}_{\mathrm{corr}}\right)$ in a pure solution and in an inhibitor-containing solution. Without stirring, it was $-45.5 \mathrm{mV}\left(25^{\circ} \mathrm{C}\right),-16.2 \mathrm{mV}\left(50^{\circ} \mathrm{C}\right)$, and $-17.1 \mathrm{mV}\left(75^{\circ} \mathrm{C}\right)$. Consequently, the inhibitor under study is of a mixed type, controlling the anode and cathode reactions simultaneously [38-40]. The idea about the mixed nature of the inhibitor under research is confirmed by slight changes in the slopes of the anode $\left(\beta_{\mathrm{a}}\right)$ and cathode $\left(\beta_{\mathrm{k}}\right)$ sections of the Tafel curves (Table 2).

With an increase in inhibitor concentration, we observed a shift in the corrosion potential to the positive side and a decrease in the corrosion rate $\left(i_{\text {corr }}\right)$ for each temperature regime separately (Figure 5). Inhibitor adsorption on the steel surface caused a change in the double layer structure and in the kinetics of electrochemical reactions. At the same time, it protected steel from the effects of a corrosive medium, making it difficult for metal ion atoms to pass from the lattice into the solution.

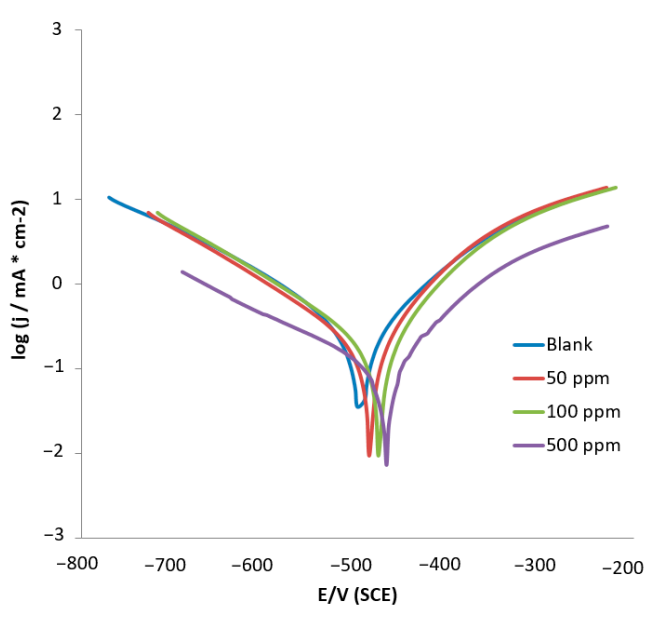

(a)

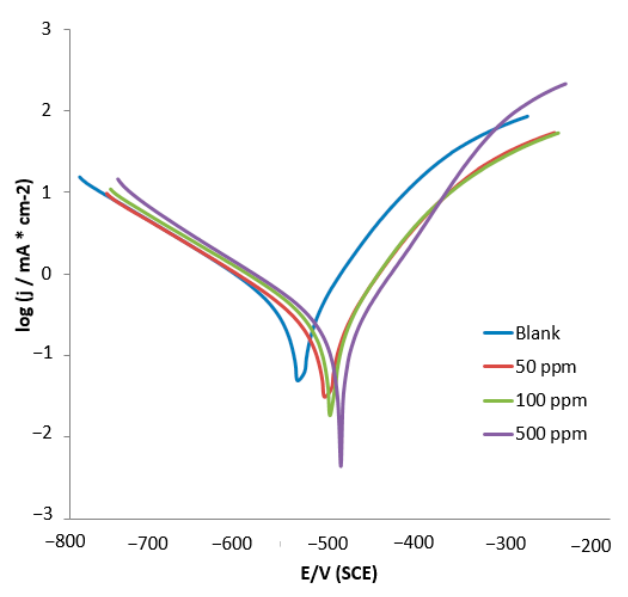

(c)

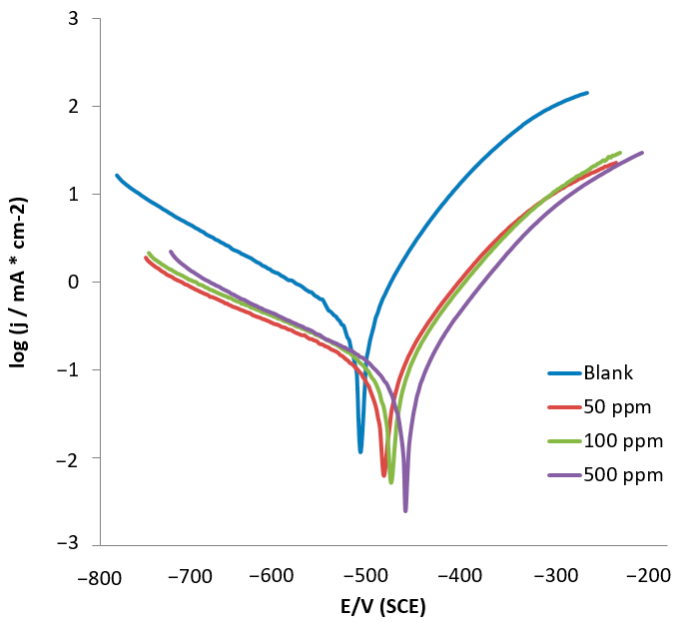

(b)

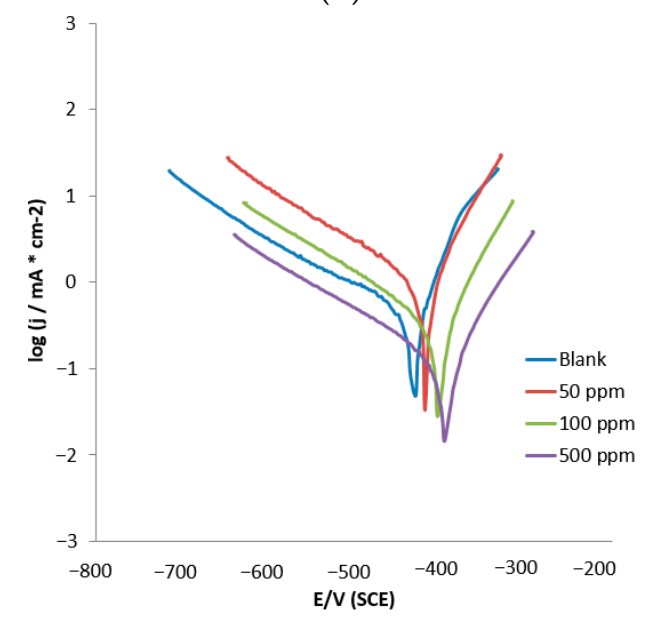

(d)

Figure 5. Cont. 


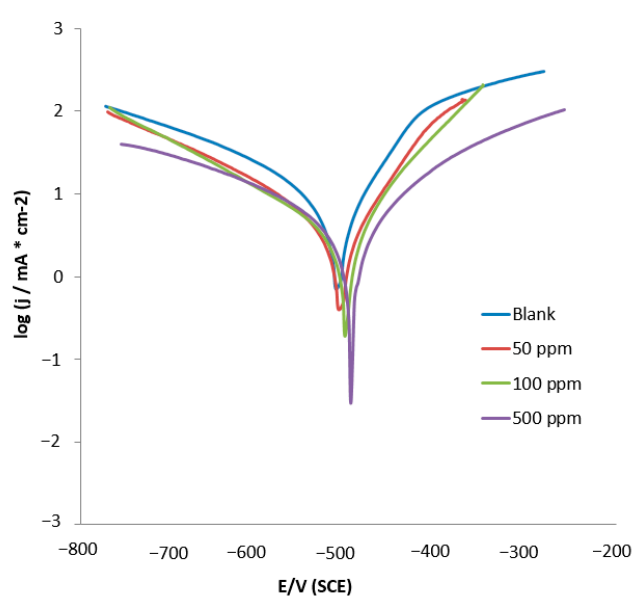

(e)

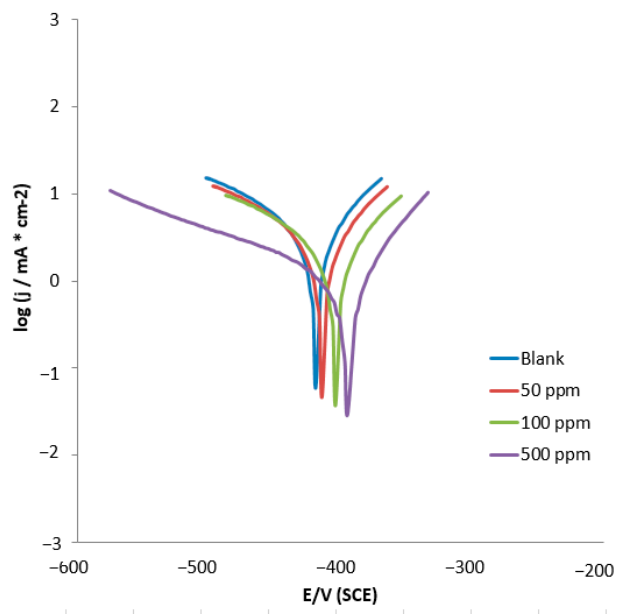

(f)

Figure 5. Tafel curves for CS corrosion in the absence and presence of $t B-W P U$ inhibitor in $2 \mathrm{M} \mathrm{HCl}$ solution at different temperatures $(\mathbf{a}, \mathbf{c}, \mathbf{e}) \mathrm{w} / \mathrm{o}$ stirring; (b,d,f) with stirring; (a,b) $25{ }^{\circ} \mathrm{C} ;(\mathbf{c}, \mathbf{d}) 50{ }^{\circ} \mathrm{C}$; $(\mathbf{e}, \mathbf{f}) 75^{\circ} \mathrm{C}$.

Comparison of data on the effectiveness of inhibition in conditions of temperature changes up to $75^{\circ} \mathrm{C}$ showed a decrease in efficiency against the background of an increase in the rate of corrosion, which made it possible to identify the optimal range of concentrations and temperatures for $t B-W P U-500 \mathrm{ppm}$ and $25-50{ }^{\circ} \mathrm{C}$.

Coverage ratio of the electrode surface with inhibitors rapidly decreases with a potential shift in the positive direction, and the proportion of current falling on the free surface increases [41-43]. In this regard, the anode and cathode polarization curves in inhibited and non-inhibited electrolytes converge, as can be seen in Figure 5a,c,e.

Table 2 shows that reference reagent Armohib CI-28 at concentrations of 50-500 ppm reduced the rate of corrosion with an efficiency of up to $96 \%$. Stirring the solution reduces the inhibition coefficient by $24.5 \%$ to $71.5 \%$ at $500 \mathrm{ppm}$. The inhibition coefficient decreased by $28.8 \%$ for $t B-W P U$ at $25^{\circ} \mathrm{C}$ and 500 ppm with stirring.

\subsubsection{Electrochemical Impedance Spectroscopy (EIS)}

The steel corrosion process was studied using electrochemical impedance spectroscopy (EIS). This technique is widely used to study corrosion processes, since it allows acquiring information on the kinetics and mechanisms of metal destruction and on the adsorption of inhibitors, without changing the state of the metal/solution interface. Quantitative analysis of the frequency dependence of the impedance based on the selected equivalent circuit allows to interpret its elements in accordance with the physicochemical nature of the processes running on the electrodes.

Figure 6 shows a Nyquist plot that combines the amplitude-frequency and phasefrequency characteristics of steel on a single plane. Each point of the Nyquist plot represents an impedance at a single frequency. Low-frequency impedance values are located on the right side of the plot, while the high-frequency ones are on the left side. The Nyquist plot has one major drawback: It is not known to which frequency the points of the curve belong.

Nyquist graphs are of irregular semicircle shape, both in the background solution and in the presence of inhibitors (Figure 6), and with increasing inhibitor concentration, the diameter of the semicircles increases.

In Nyquist plots, the intersection of loops on the horizontal axis and the diameter of the capacitive loop represents charge transfer resistance $\left(R_{c t}\right)$. The greater the $R_{c t}$, the higher the corrosion resistance. $R_{c t}$ increases on increasing the inhibitor concentration. Deviation from the ideal semicircle is due to the surface heterogeneity and roughness. The largest diameter of the curves (Figure 6a) is observed for impedance spectra with the $t B-W P U$ 
concentration of $500 \mathrm{ppm}$ at $25^{\circ} \mathrm{C}$ without stirring, which indicates the inhibitor adsorption on the metal surface.

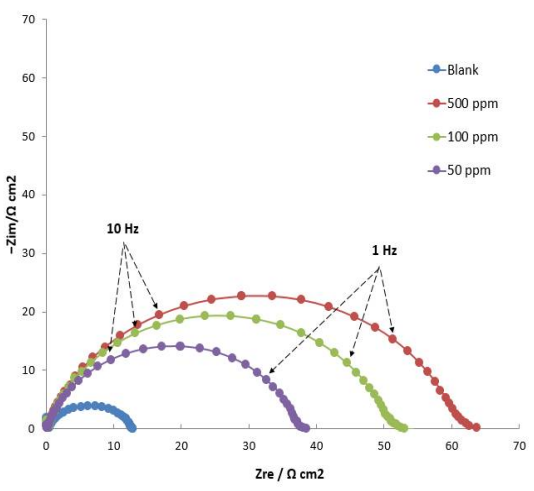

(a)

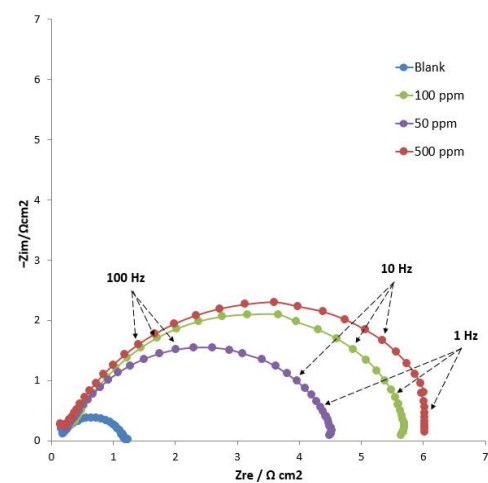

(b)

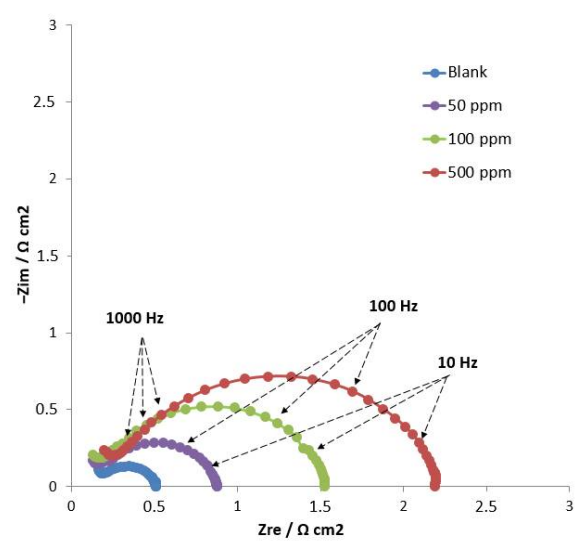

(c)

Figure 6. Nyquist plots for $C S$ in $2 \mathrm{M} \mathrm{HCl}$ with various concentrations of $t B-W P U$ at (a) 25, (b) 50, (c) $75{ }^{\circ} \mathrm{C}$.

As the temperature increases, the impedance response changes significantly, showing two capacitive loops on the Nyquist graph. One capacitive circuit is formed due to the capacity of the double layer in higher frequency ranges, and the other due to the continuous process of adsorption and desorption at lower frequencies [44]. With increasing temperature, the diameters of the capacitive loops on decreases. However, their shape remains unchanged, which indicates a change in the properties of the double electric layer against the background of the immutability of the corrosion mechanism.

An equivalent scheme known in the literature was used to analyse the EIS results (Figure 7) [14,45]. This scheme corresponds to the formation of a monolayer of inhibitor molecules adsorbed on the steel surface. Since the capacitive loops had irregularities, which indicates the heterogeneity of electrodes in the equivalent circuit (Figure 7), a constant phase element (CPE) was introduced [46]. An equivalent circuit also contains solution resistance, $R_{s}$, and polarization resistance, $R_{c t}$ [47]. The Chi-square coefficient $\left(\chi^{2}\right)$ was about $10^{-3}$, which indicates the accuracy of the fit.

With an increase in inhibitor concentration, the polarization resistance value increases, which can be associated with the formation of a polymer film on the metal surface due to the action of charge transfer [48-51].

Constant phase element (CPE) is mathematically expressed as follows [40]:

$$
Z_{\mathrm{CPE}}=Y_{0}^{-1}(j \omega)^{-n}
$$


where $Y_{0}$ is the CPE magnitude, $j$ is the imaginary unit, $\omega$ is the angular frequency, and $n$ is the phase shift providing more details on the surface inhomogeneity [52].

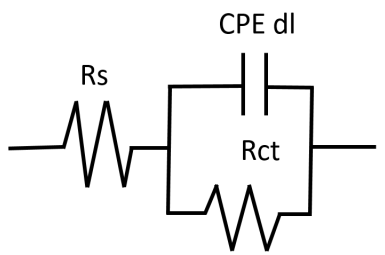

Figure 7. Equivalent circuit model deployed in fitting the experimental impedance data. $R_{S}$ and $R_{c t}$ mean the magnitudes of solution and the charge transfer resistance, respectively.

With an increase in inhibitor concentration, the CPE values decrease (Table 3). This can be explained by an increase in the inhibitor adsorption rate and, consequentially, an increase in the protective layer thickness $[53,54]$. This also confirms the increase in the capacitive loop radius due to the presence of an obstacle in the surface film to the charge transfer process.

Table 3. EIS parameters at various temperatures for $\mathrm{CS}$ in $2 \mathrm{M} \mathrm{HCl}$ with various concentrations of $t B-W P U$.

\begin{tabular}{|c|c|c|c|c|c|c|}
\hline \multirow{2}{*}{ Inhibitor Concentration } & \multirow{2}{*}{$R_{S}\left(\Omega \mathrm{cm}^{2}\right)$} & \multirow{2}{*}{$R_{c t}\left(\Omega \mathrm{cm}^{2}\right)$} & \multicolumn{2}{|l|}{$\mathrm{CPE}$} & \multirow{2}{*}{$x^{2}\left(10^{-3}\right)$} & \multirow{2}{*}{$\eta \%$} \\
\hline & & & $Y_{0} \times 10^{-3}\left(\Omega^{-1} \mathrm{~s}^{\mathrm{n}} \mathrm{cm}^{-2}\right)$ & $n$ & & \\
\hline \multicolumn{7}{|c|}{$25^{\circ} \mathrm{C}$ w/o Stirring } \\
\hline 500 ppm & 0.39 & 63.05 & 1.154 & 0.837 & 5.2 & 83.04 \\
\hline $100 \mathrm{ppm}$ & 0.40 & 42.11 & 1.203 & 0.842 & 2.9 & 74.61 \\
\hline 50 ppm & 0.37 & 38.18 & 1.557 & 0.880 & 3.9 & 72.00 \\
\hline $0 \mathrm{ppm}$ & 0.92 & 10.69 & 1.898 & 0.825 & 1.6 & - \\
\hline \multicolumn{7}{|c|}{$25^{\circ} \mathrm{C}$ with stirring } \\
\hline 500 ppm & 0.87 & 45.12 & 1.38 & 0.885 & 3.5 & 59.51 \\
\hline 100 ppm & 0.42 & 42.03 & 1.63 & 0.815 & 2.7 & 56.53 \\
\hline 50 ppm & 0.54 & 28.7 & 1.93 & 0.841 & 4.9 & 36.34 \\
\hline $0 \mathrm{ppm}$ & 0.54 & 18.27 & 2.11 & 0.821 & 2.6 & - \\
\hline \multicolumn{7}{|c|}{$50{ }^{\circ} \mathrm{C}$ w/o stirring } \\
\hline $500 \mathrm{ppm}$ & 0.44 & 5.98 & 0.9 & 0.846 & 9.2 & 79.26 \\
\hline 100 ppm & 0.29 & 5.69 & 1.4 & 0.839 & 7.9 & 78.21 \\
\hline 50 ppm & 0.17 & 4.95 & 1.5 & 0.852 & 3.7 & 74.95 \\
\hline 0 ppm & 0.24 & 1.24 & 1.9 & 0.840 & 1.3 & - \\
\hline \multicolumn{7}{|c|}{$50^{\circ} \mathrm{C}$ with stirring } \\
\hline 500 ppm & 0.32 & 1.83 & 3.1 & 0.845 & 5.1 & 59.02 \\
\hline 100 ppm & 0.23 & 1.43 & 4.0 & 0.855 & 4.5 & 47.55 \\
\hline 50 ppm & 0.16 & 1.03 & 4.9 & 0.860 & 3.8 & 27.18 \\
\hline 0 ppm & 0.22 & 0.75 & 6.8 & 0.832 & 1.4 & - \\
\hline \multicolumn{7}{|c|}{$75^{\circ} \mathrm{C}$ w/o stirring } \\
\hline 500 ppm & 0.22 & 2.01 & 1.02 & 0.849 & 3.2 & 63.68 \\
\hline 100 ppm & 0.13 & 1.5 & 1.21 & 0.851 & 6.8 & 51.33 \\
\hline 50 ppm & 0.11 & 0.85 & 1.52 & 0.865 & 5.3 & 14.12 \\
\hline $0 \mathrm{ppm}$ & 0.15 & 0.73 & 1.56 & 0.841 & 9.8 & - \\
\hline \multicolumn{7}{|c|}{$75{ }^{\circ} \mathrm{C}$ with stirring } \\
\hline 500 ppm & 0.65 & 1.24 & 1.01 & 0.839 & 0.1 & 54.84 \\
\hline 100 ppm & 0.15 & 0.92 & 1.3 & 0.841 & 2.1 & 39.13 \\
\hline 50 ppm & 0.54 & 0.64 & 1.21 & 0.850 & 8.4 & 12.50 \\
\hline 0 ppm & 0.43 & 0.56 & 1.6 & 0.835 & 9.3 & - \\
\hline
\end{tabular}


$\eta \%$ was calculated from the charge transfer [55]:

$$
\eta \%=\frac{R_{c t}-R_{c t}^{0}}{R_{c t}} * 100
$$

where $R_{c t}^{0}$ and $R_{c t}$ are the charge transfer resistance values in the absence and presence of $t B-W P U$, respectively.

Nyquist graphs contain frequency as an implicit variable. Such graphs are informative for understanding the processes running in the system, but no frequency as an explicit variable is a significant obstacle to understanding frequency dependencies. Representing experimental data in form of the impedance dependence on frequency, the Bode graph (Supplementary Materials) is constructed for the real and imaginary impedance components. Bode graphs showed an increase in the phase angle peaks, which indicates an increase in the degree of adsorption and inhibitory effect in the presence of $t B-W P U$. Absolute impedance values at low frequency are higher in the presence of $t B-W P U$, which also confirms the inhibitor adsorption on the steel surface $[56,57]$.

\subsection{Adsorption Isotherm and Thermodynamic Calculations}

To better understand the corrosion inhibition mechanism, we studied adsorption isotherms, adsorption constants, and Gibbs free energies of adsorption. Since in our experiment, the Langmuir isotherm agrees well with the experimental points $\left(R^{2}>0.999\right)$, the calculation was carried out according by the following equation [58]:

$$
K_{\text {ads }} C=\frac{\theta}{1-\theta}
$$

where $\theta, C$, and $K_{a d s}$ are surface coverage, inhibitor concentration, and the adsorption/ desoprion equilibrium constant, respectively. $\theta$ values were defined as $\% I E / 100$ (from Table 2).

As shown in Figure 8, we plotted $C / \theta$ against $C$ to obtain the linear behavior of plots with regression coefficients close to the unity $\left(R^{2}>0.999\right)$. $K_{a d s}$ values were obtained from the intercept of the linear plots. Only linear dependence was not obtained for the system with $t B-W P U$ at $75^{\circ} \mathrm{C}$ under stirring conditions. Deviation from unity in the slope values is related to its IE value. Larger IE value of the inhibitor has smaller deviation from unity [59]. For non-stirred systems, the smallest slope deviation from unity is observed for Armohib $\mathrm{CI}-28$ at $25{ }^{\circ} \mathrm{C}$. Next comes $t B-W P U$ at $25{ }^{\circ} \mathrm{C}$, for which the slope value increases with increasing temperature, which means a gradual decrease in the inhibition efficiency. It is clearly seen that, when going from 25 to $50{ }^{\circ} \mathrm{C}$, the slope changes slightly, while it reaches 1.82 when going from 50 to $75^{\circ} \mathrm{C}$.

The relationship between $K_{a d s}$ and $\Delta G_{a d s}$ is defined as follows [60]:

$$
\Delta G_{a d s}=-R T \ln \left(1 \times 10^{6} K_{a d s}\right)
$$

where $T, R$, and $1 \times 10^{6}$ are thermodynamic temperature, standard gas constant, and water molecules concentration in the solution $\left(\mathrm{mg} \mathrm{L}^{-1}\right)$, respectively.

$\Delta G_{a d s}$ value below zero indicates the spontaneous inhibitor adsorption on the metal and shows the stability of the film formed on the CS surface. Typically, $\Delta G_{\text {ads }}$ value may be used to identify the adsorption type of inhibitors on a metal surface [61]. Depending on the values of $\Delta G_{a d s}$, it can be physisorption or chemisorption. The former one is related to weak interactions, such as electrostatic ones, between the inhibitor molecule and Fe atoms, and the $\Delta G_{a d s}$ values are about $-20 \mathrm{~kJ} \mathrm{~mol}^{-1}$; while the second one involves forming chemical bonds due to sharing or transferring electrons from inhibitor to metal surface, and the $\Delta G_{a d s}$ values are under $-40 \mathrm{~kJ} \mathrm{~mol}^{-1}[46]$. 


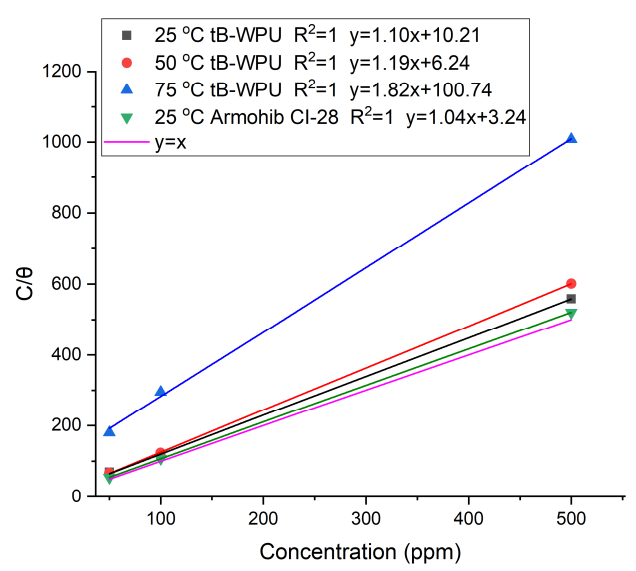

(a)

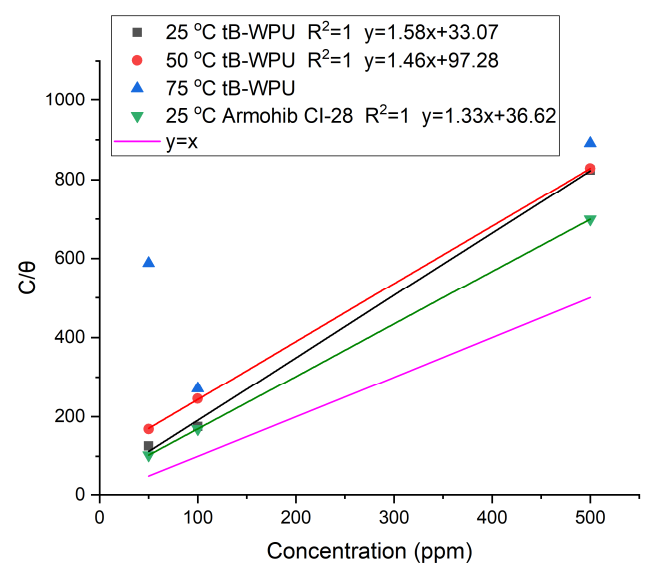

(b)

Figure 8. Langmuir adsorption isotherm for $t B-W P U$ and Armohib CI-28 on carbon steel at different temperatures (a) without stirring and (b) with stirring, obtained from the PDP measurements.

Table 4 shows all the results obtained from our electrochemical studies. The Gibbs free energy values are observed to be in the range from -20 to $-30 \mathrm{~kJ} / \mathrm{mol}$, which indicates physical adsorption. For systems with $t B-W P U$ without stirring, the value of the Gibbs energy increases in modulus when going from 25 to $50{ }^{\circ} \mathrm{C}$, reaching Armohib values, and then drops at $75^{\circ} \mathrm{C}$. The values slightly decrease in modulus upon stirring, which may indicate a slight difficulty in binding to the surface.

Table 4. Values of constants and Gibbs free energies of adsorption for $t B-W P U$ and Armohib CI-28 (from PDP experiments).

\begin{tabular}{cccccc}
\hline Sample & Temperature, ${ }^{\circ} \mathbf{C}$ & $\boldsymbol{K}_{\text {ads }}$ & $\Delta \boldsymbol{G}_{\boldsymbol{a d s}}, \mathbf{k J} / \mathbf{m o l}$ & $\boldsymbol{R}^{\mathbf{2}}$ & Slope \\
\hline \multirow{2}{*}{$t B$-WPU } & 25 & Without stirring & & \\
& 50 & 0.10 & -28.54 & 1 & 1.10 \\
\cline { 2 - 6 } & 75 & 0.16 & -32.19 & 1 & 1.19 \\
\hline Armohib CI-28 & 25 & 0.01 & -26.66 & 1 & 1.82 \\
\hline \multirow{2}{*}{$t B-W P U$} & 25 & 0.31 & -31.34 & 1 & 1.04 \\
\cline { 2 - 6 } & 50 & With stirring & -25.55 & 1 & 1.58 \\
\hline Armohib CI-28 & 75 & 0.03 & -24.75 & 1 & 1.46 \\
\hline
\end{tabular}

\subsection{Activation Energy and Temperature Effect on Corrosion Kinetics}

The Arrhenius equation was used to calculate activation energy [14]:

$$
\ln i_{\text {corr }}=\ln A-\frac{E_{a}}{R T}
$$

where $i_{\text {corr }}$ (Table 2), $A, R$, and $T$ are corrosion current density, Arrhenius constant, gas constant, and the experiment temperature, respectively.

$E_{a}$ (Table 5) was determined by the angle of inclination of the linear of the corrosion current density on temperature (Figure 9a). For solutions with $t B-W P U$, the activation energy value is greater than that for the solution of $2 \mathrm{M} \mathrm{HCl}$, which can be attributed to the physical adsorption of $t B-W P U$ molecules with the steel surface $[56,62,63]$. To evaluate the 
activation enthalpy $\left(\Delta H^{0}{ }_{a d s}\right)$ and entropy $\left(\Delta S^{0}{ }_{a d s}\right), \log \left(i_{c o r r} / T\right)$ dependence was used as compared to $1 / T$ (Figure $9 \mathrm{~b}$ ) [64].

Table 5. Activation energy $\left(E_{a}\right)$, regression coefficient $\left(R^{2}\right)$, enthalpy $\left(\Delta H^{0}{ }_{a}\right)$, and $\left(\Delta S^{0}{ }_{a}\right)$ calculated for $\mathrm{CS}$ in $2 \mathrm{M} \mathrm{HCl}$.

\begin{tabular}{|c|c|c|c|c|}
\hline Sample & $E_{a}\left(\mathrm{~kJ} \mathrm{~mol}^{-1}\right)$ & $\Delta H_{a d s}^{0}\left(\mathrm{~kJ} \mathrm{~mol}^{-1}\right)$ & $\Delta S_{a d s}^{0}\left(\mathrm{~J} \mathrm{~mol}^{-1} \mathrm{~K}^{-1}\right)$ & $R^{2}$ \\
\hline Blank & 54.51 & 16.38 & -142.12 & 0.98 \\
\hline$t B-W P U$ & 91.16 & 39.60 & -74.54 & 0.96 \\
\hline Armohib CI-28 & 106.20 & 46.10 & -62.20 & 0.99 \\
\hline
\end{tabular}

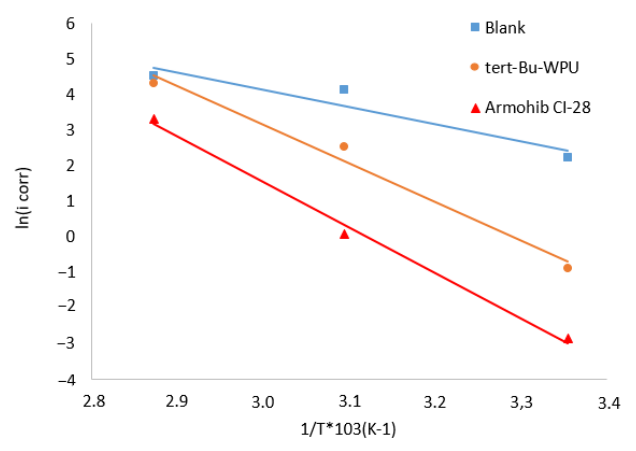

(a)

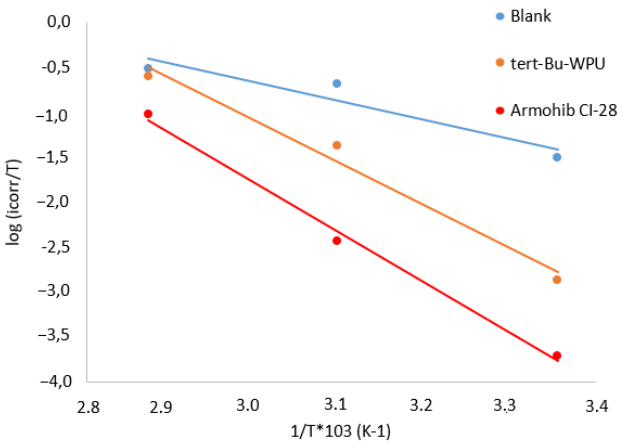

(b)

Figure 9. Activation plots (a) and transition-state plots (b) of CS blank, with 100 ppm of $t B$-WPU, and with Armohib CI-28.

Activation enthalpy $\left(\Delta H^{0}{ }_{a d s}\right)$ and entropy $\left(\Delta S^{0}{ }_{a d s}\right)$ can also be calculated from the transition state [65]:

$$
i_{\text {corr }}=\frac{R T}{N h} \exp \frac{\Delta S_{a}^{0}}{R} \exp \frac{-\Delta H_{a}^{0}}{R T}
$$

where $h$ refers to Planck's constant and $N$ provides the number of Avogadro.

As the values of the activation barrier were found to be rather high (Table 5), it can be argued that reaching the adsorption equilibrium requires considerable time. This was considered when performing the adsorption measurements.

Enthalpy values $\left(\Delta H^{0}{ }_{a d s}\right)$ were calculated from the slope of the $\log j_{c o r r} / T$ graph from $1 / T$, while the graph intersection with the $\mathrm{Y}$ axis provided the values of activation entropy $\left(\Delta S^{0}{ }_{a d s}\right)$ (Table 5). Positive values of $\Delta H^{0}{ }_{a d s}$ confirmed the inhibitory effect of $t B-W P U$ in an acid solution $[53,66]$. A more positive value of $\Delta S^{*}$ in a solution with $t B$-WPU suggests an increase in the randomness of the dissolution process and, consequentially, an increase in the inhibitor adsorption degree [67-69].

\subsection{Surface Morphology Analysis}

To visualize the $t B-W P U$ action, coupons (CS) aged in $2 \mathrm{M} \mathrm{HCl}$ at different temperatures were tested using profilometry. Figure 10 shows $3 \mathrm{D}$ images for coupon surfaces after having been corroded at 25,50 , and $75{ }^{\circ} \mathrm{C}$ w/o or with $t B-W P U$ or Armohib CI-28 under nonstirring conditions.

Reduced surface roughness can be seen in systems with inhibitors. Surface images show the drop in corrosion inhibition performance with increasing temperature. Generally, it can be said that the inhibition efficiency reaches its maximum at room temperature. 


\section{$25{ }^{\circ} \mathrm{C}$}
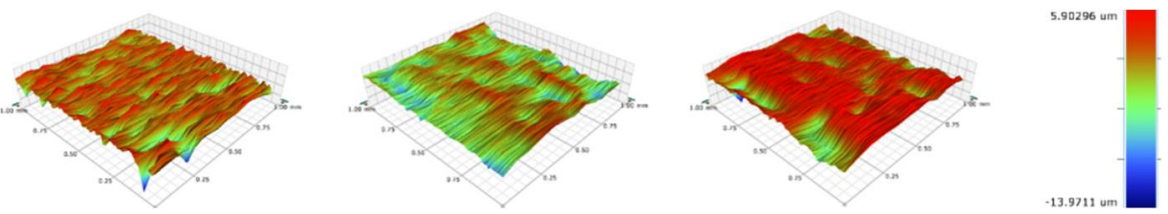

$50{ }^{\circ} \mathrm{C}$
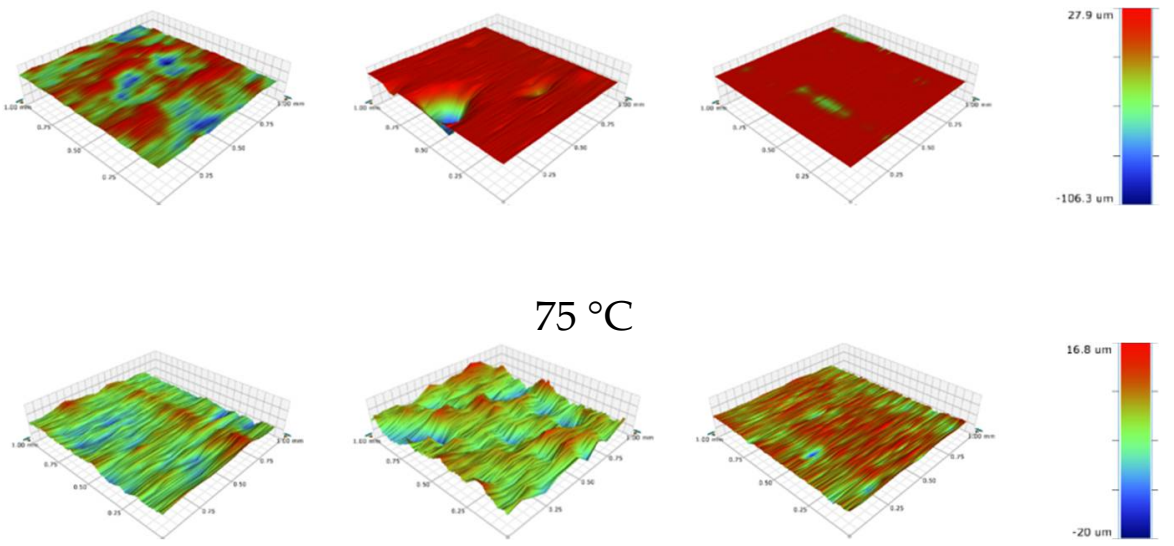

\section{w/o inhibitor $t B-W P U$ Armohib CI-28}

Figure 10. Surface topography of steel coupons.

\subsection{Quantum-Chemical Calculations}

Based on the data obtained from periodic DFT calculations, it can be concluded that the $\mathrm{mim}^{-}$molecule is adsorbed on $\mathrm{Fe}$ (100) nearly parallelly (in horizontal orientation). As seen from Table 6, bonding to the metal surface is provided mainly by carboxyl and amino groups. Short $\mathrm{Fe}-\mathrm{O}, \mathrm{Fe}-\mathrm{N}$, and $\mathrm{Fe}-\mathrm{C}$ distances clearly indicate the formation of chemical bonds. The bond nature originates presumably from the interaction of molecule donor groups with acceptor $d$-orbitals of Fe. This induces a shift of the iron $d$-band peak towards the region of deeper electronic energies relative to the Fermi level (see Figure 11), which additionally indicates the formation of binding states. Cyclohexane ring, $-\left(\mathrm{CH}_{2}\right)_{2}-\mathrm{O}_{-}-\mathrm{CH}_{2}-$ $\mathrm{COOH}$ and $-\left(\mathrm{CH}_{2}\right)_{2}-\mathrm{CH}_{2} \mathrm{OH}-\mathrm{COO}^{-}$tails are turned to solution bulk and do not directly contact the metal surface (Figure 12), which additionally ensures the inhibiting properties of the adsorbed $\mathrm{mim}^{-}$molecules on the iron surface.

Table 6. Bond lengths between $\mathrm{Fe}$ and $\mathrm{O} / \mathrm{N} / \mathrm{C}$ atoms forming chemical bonds in the adsorption of mim $^{-}$at $\mathrm{Fe}(100)$.

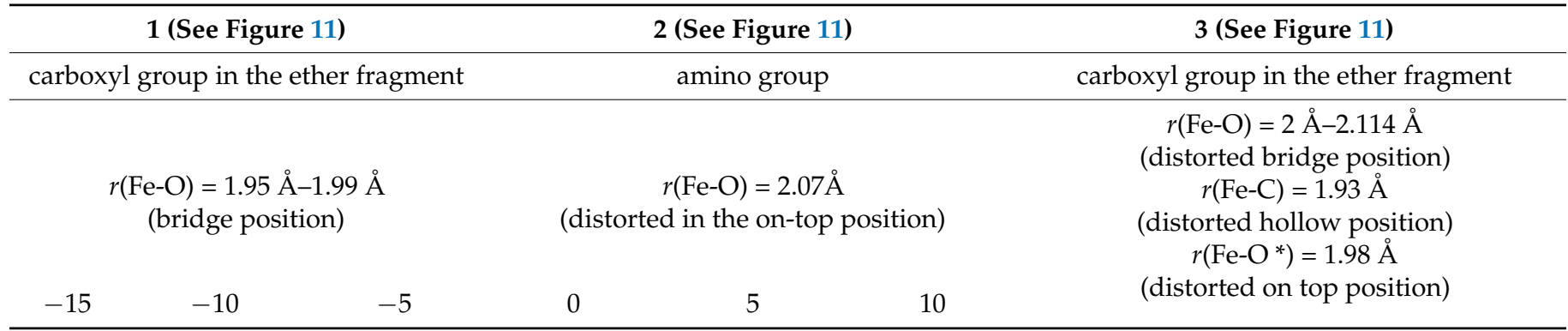




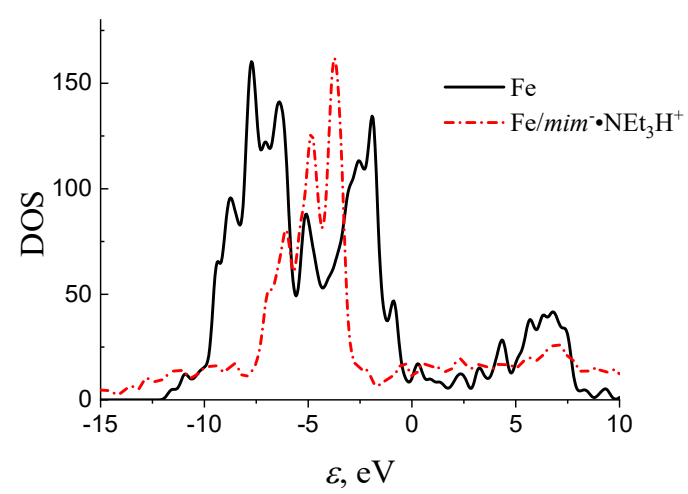

Figure 11. Density of electronic states calculated for the $\mathrm{Fe}(100)$ and $\mathrm{Fe}(100) / \mathrm{mim}^{-} \cdot \mathrm{Net}_{3} \mathrm{H}^{+}$model systems; Fermi level taken as zero.

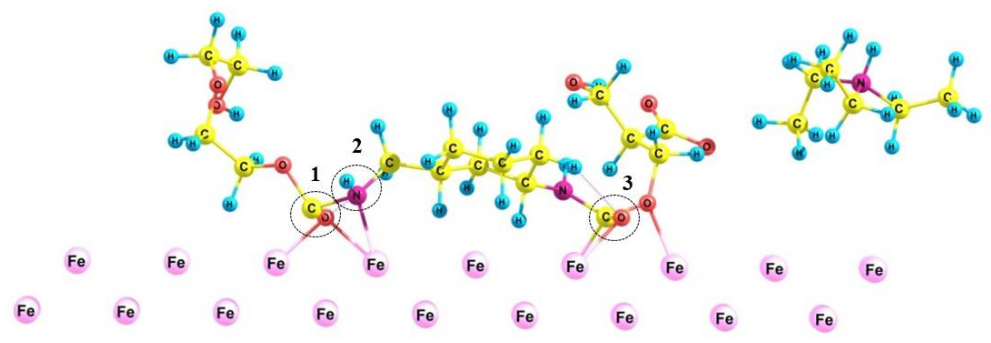

(a)

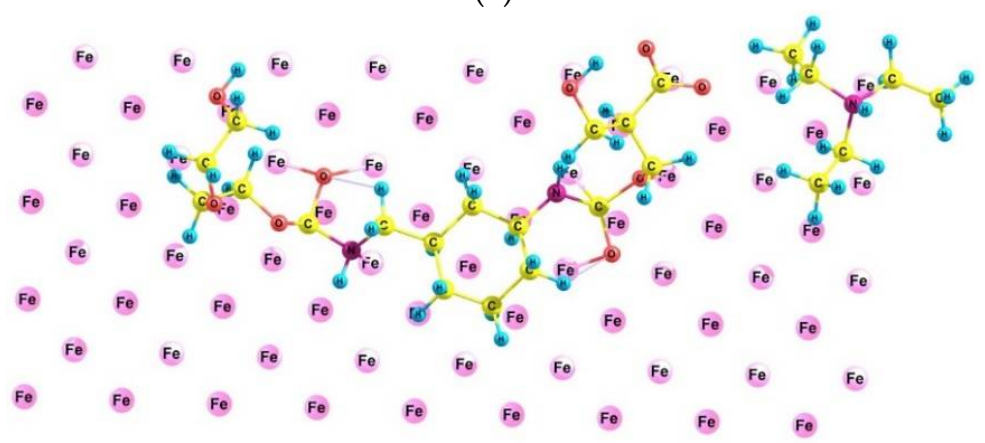

(b)

Figure 12. Optimized geometry of the inhibitor molecule and cation adsorbed the $\mathrm{Fe}(100)$ surface, forming a monolayer: Side view (a) and top view (b).

Adsorption energy of $\mathrm{mim}^{-}$and $\mathrm{NEt}_{3} \mathrm{H}^{+}$forming a monolayer on $\mathrm{Fe}(100)$ was initially calculated for the gas phase (vacuum), see Table 7. The relevant value was found to be quite high $(-6.5 \mathrm{eV})$. On the other hand, the solvent environment significantly reduce this quantity. We try to roughly address this effect further; more accurate estimations require molecular dynamics simulations (see, for example, [55]). First, we should consider the desorption of $\mathrm{H}_{2} \mathrm{O}$ molecules from the electrode surface. For the $\mathrm{mim}^{-}$molecule on $\mathrm{Fe}(100)$, the number of water molecules desorbed amounts to about 10, which can be found in Figure 12. Second, a partial dehydration of $\mathrm{min}^{-}$and $\mathrm{NEt}_{3} \mathrm{H}^{+}$should also be considered:

$$
\Delta E_{a d s}^{\text {solv }} \approx \Delta E_{a d s}^{v a c}+\frac{1}{2}\left|\Delta G_{h y d r}\left(\operatorname{mim}^{-}\right)\right|+\frac{1}{2}\left|\Delta G_{h y d r}\left(N E t_{3} H^{+}\right)\right|+n_{w} \Delta E_{H_{2} \mathrm{O}}^{d e s}
$$

where the factor of $1 / 2$ nearly considers reducing the hydration energy at the electrode surface, as compared to the solution bulk. 
Table 7. Adsorption energy of the $\mathrm{mim}^{-} \cdot \mathrm{NEt}_{3} \mathrm{H}^{+}$monolayer at $\mathrm{Fe}(100)$ from vacuum $\left(\Delta E_{a d s}^{v a c}\right)$, Gibbs hydration energies of $\mathrm{mim}^{-}$and $\mathrm{NEt}_{3} \mathrm{H}^{+}$in solution bulk $\left(\Delta G_{h y d r}\right)$, number of desorbed water molecules $\left(n_{w}\right)$, and desorption energy of a water molecule from the $\mathrm{Fe}(100)$ surface $\left(\Delta E_{\mathrm{H}_{2} \mathrm{O}}^{\text {des }}\right)$.

\begin{tabular}{cccc}
\hline$\Delta E_{a d s}^{v a c *}, \mathrm{eV}$ & $\Delta G_{h y d r}, \mathrm{eV}$ & $n_{w}$ & $\Delta E_{\mathrm{H}_{2} \mathrm{O}^{\prime}}^{\text {des }} \mathbf{e V}$ \\
\hline-6.5 & $\begin{array}{c}-2.92\left(\mathrm{mim}^{-}\right) \\
-2.11\left(\mathrm{NEt}_{3} \mathrm{H}^{+}\right)\end{array}$ & 10 & $0.4^{* *}$ \\
\hline
\end{tabular}

${ }^{*} \Delta E_{\text {ads }}^{\text {vac }}=E_{\text {tot }}\left(\mathrm{Me}-\mathrm{mim}^{-} \cdot \mathrm{NEt}_{3} \mathrm{H}^{+}\right)-E_{\text {tot }}(\mathrm{Me})-E_{\text {tot }}\left(\mathrm{mim}^{-} \cdot \mathrm{NEt}_{3} \mathrm{H}^{+}\right)$, where $\mathrm{mim}^{-} \cdot \mathrm{NEt}_{3} \mathrm{H}^{+}$notes a $\mathrm{c}(2 \times 2)$ monolayer (Figure 13) without the $\mathrm{Fe}(100)$ substrate. ${ }^{* *}$ Averaged value obtained from the recent DFT calculations: 0.43 [70], 0.38 [71], and 0.39 [72]. All these works found the on-top position for a water molecule adsorbed to be the most preferable.

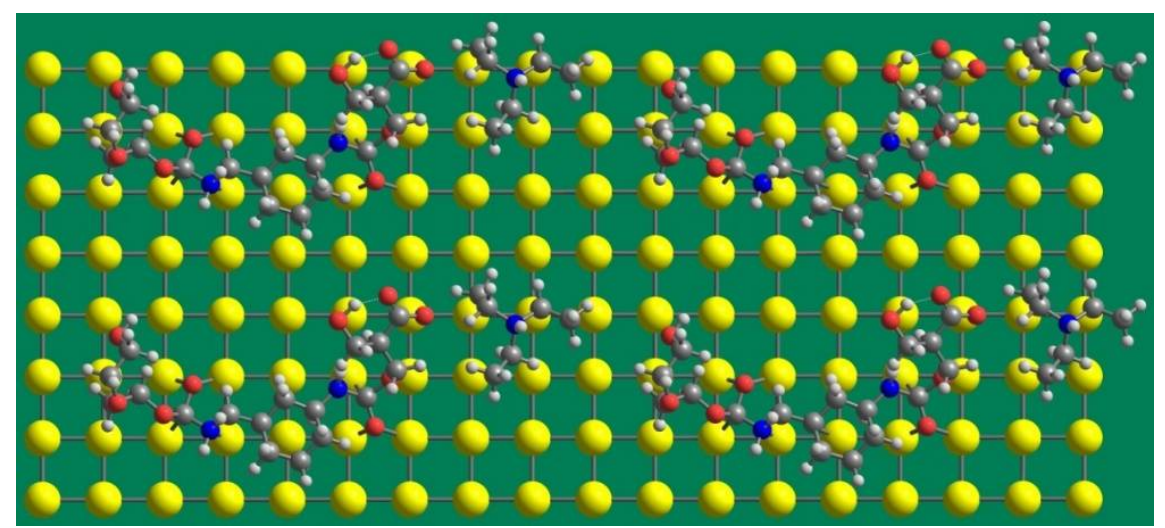

Figure 13. Fragment of a monolayer formed at the Fe(100) surface by the adsorbed inhibitor molecules and $\mathrm{NEt}_{3} \mathrm{H}^{+}$cations. The second layer of Fe atoms is not shown for simplicity.

The adsorption energy from the aqueous solution was thus reduced drastically and found to be $-0.3 \mathrm{eV}$. Therefore, in our case, a reversible adsorption/desorption is expected. Surprisingly, this estimate is in good agreement with the Gibbs adsorption energy obtained experimentally (see Section 3.3). Note that, according to our calculations, on formation of a contact $\mathrm{mim}^{-} \cdot \mathrm{NEt}_{3} \mathrm{H}^{+}$ionic pair (see Figure 12), Gibbs energy value was found to be +0.25 $\mathrm{eV}$. Thus, an ionic associate $\mathrm{mim}^{-} \cdot \mathrm{NEt}_{3} \mathrm{H}^{+}$exists in the solution most likely as a couple separated by solvent sheath.

Adsorption bond is often described in terms of an approach based on the analysis of the frontier orbitals of a molecule and reactivity descriptors (see, for example, [70]). This method, however, does not seem to work well in our case. Figure 14 shows that only one frontier orbital $\left(\mathrm{LUMO}_{2}\right)$ contributes to the active center (the carboxyl group of ether fragment, see Table 2).

A deeper insight into the interplay between the adsorption of organic molecules and various redox processes on the steel surface/electrolyte solution interface can be gained in the framework approach discussed recently in work [73]. 


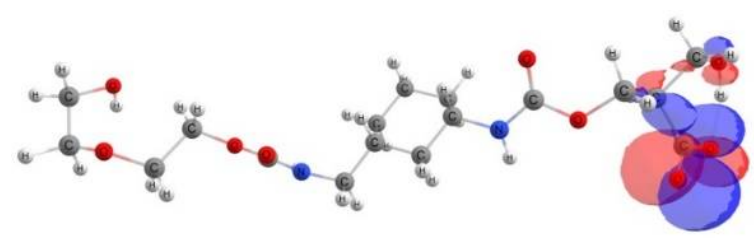

$\mathrm{HOMO}_{1}$

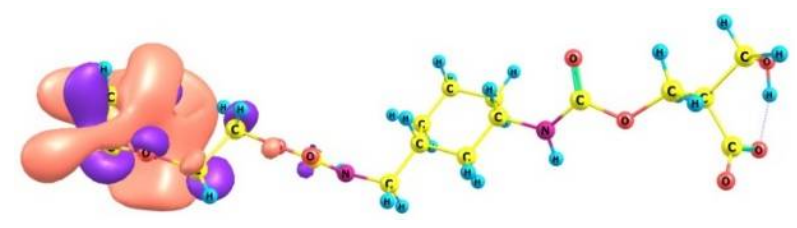

$\mathrm{LUMO}_{1}$

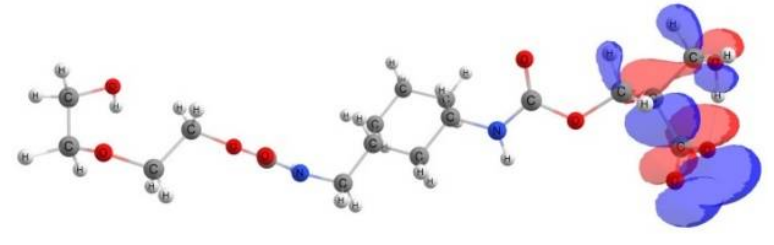

$\mathrm{HOMO}_{2}$

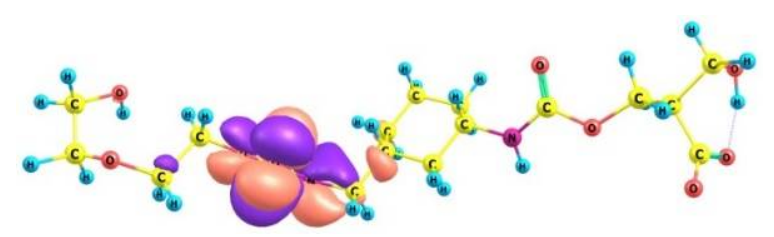

$\mathrm{LUMO}_{2}$

Figure 14. Several frontier orbitals of the mim ${ }^{-}$anion: $\mathrm{HOMO}_{1}$ and $\mathrm{LUMO}_{1}$ correspond to the real Highest Occupied and Lowest Unoccupied $\mathrm{MO}$, while $\mathrm{HOMO}_{2}$ and $\mathrm{LUMO}_{2}$ denote the first orbitals lying lower and upper the HOMO and LUMO, respectively.

\section{Conclusions}

A water-soluble polyurethane based on N-tert-butyl diethanolamine was studied to inhibit CS corrosion in an acidic environment at temperatures ranging from $25^{\circ} \mathrm{C}$ to $75^{\circ} \mathrm{C}$. It was found by the gravimetric method and electrochemical studies that with an increase in $t B-W P U$ concentration, the inhibiting efficiency increases at all temperatures investigated; this might be explained bearing in mind that temperature facilitates water desorption and partial dehydration of the inhibitor molecule, as well as the monolayer formation. However, an increase in temperature to $75^{\circ} \mathrm{C}$ also leads to increasing the corrosion rate, which weakens the inhibition effect. According to the change in corrosion potential ( $\left.\mathrm{E}_{\mathrm{corr}}\right)$ in a pure solution and in a solution containing $t B-W P U$, the latter was found to be a mixed inhibitor that simultaneously controls anode and cathode reactions.

The mechanistic picture of the inhibition looks as expected: adsorbed $t B-W P U$ molecules form a protecting (barrier) monolayer on the steel surface, which impedes the diffusion transport of $\mathrm{O}_{2}$ and $\mathrm{H}_{2} \mathrm{O}$ molecules to the surface. The estimated activation energy makes it possible to judge about the mechanism of $t B-W P U$ adsorption. The effective concentration and temperature range for $t B-W P U$ were found to be $500 \mathrm{ppm}$ and $25-50{ }^{\circ} \mathrm{C}$. A simplified, but robust model was proposed to describe the adsorption of inhibitor molecules from aqueous solution at the Fe(100) surface. The DFT calculations provide a deeper insight into the metal-adsorbate chemical bond and make it possible to estimate the adsorbate geometry and main contributions to the adsorption energy.

Supplementary Materials: The following supporting information can be downloaded at: https: / /www.mdpi.com/article/10.3390/en15051939/s1, Figure S1. Bode phase angle plots (a,c,e) and Bode modulus plots $(\mathrm{b}, \mathrm{d}, \mathrm{f})$ for $\mathrm{CS}$ in $2 \mathrm{M} \mathrm{HCl}$ in the absence and presence of different concentrations of $t B-W P U$ inhibitor.

Author Contributions: Conceptualization, S.S.V., R.S.P. and M.A.V.; methodology, S.S.V., R.S.P. and R.R.N.; validation, S.S.V., R.S.P. and M.A.V.; formal analysis, Y.F.Z., S.S.V. and R.S.P.; investigation, Y.F.Z., S.R., R.S.P., S.S.V., R.R.N. and I.R.V.; resources, M.A.V.; data curation, Y.F.Z., S.R., R.S.P., S.S.V. and I.R.V.; writing - original draft preparation, Y.F.Z., R.S.P., S.S.V. and R.R.N.; writing—review and editing, Y.F.Z., R.S.P., S.S.V. and M.A.V.; visualization, Y.F.Z., S.S.V. and R.R.N.; supervision, M.A.V.; project administration, S.S.V. and R.S.P.; funding acquisition, M.A.V. All authors have read and agreed to the published version of the manuscript.

Funding: The reported study was funded by RFBR and The Research Council of Norway (research project No. 20-55-20010). 


\section{Institutional Review Board Statement: Not applicable.}

Informed Consent Statement: Not applicable.

Conflicts of Interest: The authors declare no conflict of interest.

\section{References}

1. Lei, X.; Wang, H.; Mao, F.; Zhang, J.; Zhao, M.; Fu, A.; Feng, Y.; Macdonald, D.D. Electrochemical Behaviour of Martensitic Stainless Steel after Immersion in a $\mathrm{H}_{2} \mathrm{~S}-$ Saturated Solution. Corros. Sci. 2018, 131, 164-173. [CrossRef]

2. Fouda, A.E.-A.S.; Motaal, S.M.A.; Ahmed, A.S.; Sallam, H.B.; Ezzat, A.; El-Hossiany, A. Corrosion Protection of Carbon Steel in 2M HCl Using Aizoon canariense Extract. Biointerface Res. Appl. Chem. 2022, 12, 230-243.

3. Reynolds, M.A. A Technical Playbook for Chemicals and Additives Used in the Hydraulic Fracturing of Shales. Energy Fuels 2020, 34, 15106-15125. [CrossRef]

4. Al Juhaiman, L.A. Polyvinyl pyrrolidone as a Corrosion Inhibitor for Carbon Steel in HCl. Int. J. Electrochem. Sci. 2016, 11, $2247-2262$.

5. Bedair, M.A.; El-Sabbah, M.M.B.; Fouda, A.S.; Elaryian, H.M. Synthesis, electrochemical and quantum chemical studies of some prepared MARK surfactants based on azodye and Schiff base as corrosion inhibitors for steel in acid medium. Corros. Sci. 2017, 128, 54-57. [CrossRef]

6. Bentiss, F.; Traisnel, M.; Lagrenee, M. The substituted 1,3,4-oxadiazoles: A new class of corrosion inhibitors of mild steel in acidic media. Corros. Sci. 2000, 42, 127-146. [CrossRef]

7. Obot, I.B.; Umoren, S.A.; Ankah, N.K. Pyrazine derivatives as green oil field corrosion inhibitors for steel. J. Mol. Liq. 2019, 277, 749-761. [CrossRef]

8. Obot, I.B.; Onyeachu, I.B.; Wazzan, N.; Al-Amri, A.H. Theoretical and experimental investigation of two alkyl carboxylates as corrosion inhibitors for steel in acidic medium. J. Mol. Liq. 2019, 279, 199-207. [CrossRef]

9. Rasheeda, K.; Vijaya Alva, D.P.; Krishnaprasad, P.A.; Samshuddin, S. Pyrimidine derivatives as potential corrosion inhibitors for steel in acid medium-An overview. Int. J. Corros. Scale Inhib. 2018, 7, 48-61.

10. Rabizadeh, T.; Asl, S.K. Casein as a natural protein to inhibit the corrosion of mild steel in HCl solution. J. Mol. Liq. 2019, 276, 694-704. [CrossRef]

11. Umoren, S.A.; Obot, I.B.; Madhankumar, A.; Gasem, Z.M. Performance evaluation of pectin as ecofriendly corrosion inhibitor for X60 pipeline steel in acid medium: Experimental and theoretical approaches. Carbohydr. Polym. 2015, 124, 280-291. [CrossRef] [PubMed]

12. Umoren, S.A.; Al Ahmary, A.A.; Gasem, Z.M.; Solomon, M.M. Evaluation of chitosan and carboxymethyl cellulose as ecofriendly corrosion inhibitors for steel. Int. J. Biol. Macromol. 2018, 117, 1017-1028. [CrossRef] [PubMed]

13. Bharatiya, U.; Gal, P.; Agrawal, A.; Shah, M.; Sircar, A. Effect of Corrosion on Crude Oil and Natural Gas Pipeline with Emphasis on Prevention by Ecofriendly Corrosion Inhibitors: A Comprehensive Review. J. Bio- Tribo-Corros. 2019, 5, 35. [CrossRef]

14. Farhadian, A.; Rahimi, A.; Safaei, N.; Shaabani, A.; Abdouss, M.; Alavi, A. A theoretical and experimental study of castor oil-based inhibitor for corrosion inhibition of mild steel in acidic medium at elevated temperatures. Corros. Sci. 2020, 175, 108871. [CrossRef]

15. Gece, G. Drugs: A review of promising novel corrosion inhibitors. Corros. Sci. 2011, 53, 3873-3898. [CrossRef]

16. Rani, B.A.; Basu, B.J. Green inhibitors for corrosion protection of metals and alloys: An overview. Int. J. Corros. 2012, 2012, 1-15. [CrossRef]

17. Idress, M.; Shahril, M.A.; Zuraidin, A.S.; Jasamai, M. Experimental Investigation of Methane Hydrate Induction Time in the Presence of Cassava Peel as a Hydrate Inhibitor. Energies 2019, 12, 2314. [CrossRef]

18. Kang, S.-P.; Lee, D.; Lee, J.-W. Anti-Agglomeration Effects of Biodegradable Surfactants from Natural Sources on Natural Gas Hydrate Formation. Energies 2020, 13, 1107. [CrossRef]

19. Sastri, V.S. Green Corrosion Inhibitors, Theory and Practice; Wiley: Hoboken, NJ, USA, 2011.

20. Palou, R.M.; Olivares-Xomelt, O.; Likhanova, N.V. Environmentally friendly corrosion inhibitors. Dev. Corros. Protect. 2014, 19, 431-465.

21. Sloan, E.D. Fundamental principles and applications of natural gas hydrates. Nature 2003, 426, 353. [CrossRef]

22. Rajput, F.; Maric, M.; Servio, P. Amphiphilic Block Copolymers with Vinyl Caprolactam as Kinetic Gas Hydrate Inhibitors. Energies 2021, 14, 341. [CrossRef]

23. Moore, J.; Ver Vers, L.; Conrad, P. Understanding Kinetic Hydrate Inhibitor and Corrosion Inhibitor Interactions. In Proceedings of the Offshore Technology Conference, Houston, TX, USA, 4-7 May 2009; Volume 1, pp. 477-481.

24. Qasim, A.; Khan, M.S.; Lal, B.; Shari, A.M. A perspective on dual purpose gas hydrate and corrosion inhibitors for flow assurance. J. Pet. Sci. Eng. 2019, 183, 106418. [CrossRef]

25. Farhadian, A.; Kudbanov, A.; Varfolomeev, M.A.; Dalmazzone, D. Waterborne Polyurethanes as a New and Promising Class of Kinetic Inhibitors for Methane Hydrate Formation. Sci. Rep. 2019, 9, 9797. [CrossRef] [PubMed]

26. Farhadian, A.; Varfolomeev, M.A.; Kudbanov, A.; Rezaeisadat, M.; Nurgaliev, D.K. Waterborne polymers as kinetic/antiagglomerant methane hydrate and corrosion inhibitors: A new and promising strategy for flow assurance. J. Nat. Gas Sci. Eng. 2020, 77, 103235. [CrossRef] 
27. Farhadian, A.; Varfolomeev, M.A.; Kudbanov, A.; Gallyamova, S.R. A new class of promising biodegradable kinetic/antiagglomerant methane hydrate inhibitors based on castor oil. Chem. Eng. Sci. 2019, 206, 507-517. [CrossRef]

28. Pavelyev, R.S.; Zaripova, Y.F.; Yarkovoi, V.V.; Vinogradova, S.S.; Razhabov, S.; Khayarov, K.R.; Nazarychev, S.A.; Stoporev, A.S.; Mendgaziev, R.I.; Semenov, A.P.; et al. Performance of Waterborne Polyurethanes in Inhibition of Gas Hydrate Formation and Corrosion: Influence of Hydrophobic Fragments. Molecules 2020, 25, 5664. [CrossRef]

29. Cui, G.; Guo, J.; Zhang, Y.; Zhao, Q.; Fu, S.; Han, T.; Zhang, S.; Wu, Y. Chitosan oligosaccharide derivatives as green corrosion inhibitors for P110 steel in a carbon-dioxidesaturated chloride solution. Carbohydr. Polym. 2019, 203, 386-395. [CrossRef]

30. WonATech Electrochemical Instruments. Gateway to Electrochemistry, 2nd ed.; WonATech Co. Ltd.: Seoul, Korea, 2014; Available online: http:/ / www.zivelab.com/ctlg/WonATech.pdf (accessed on 20 November 2020).

31. Frisch, M.J.; Trucks, G.W.; Schlegel, H.B.; Scuseria, G.E.; Robb, M.A.; Cheeseman, J.R.; Scalmani, G.; Barone, V.; Petersson, G.A.; Nakatsuji, H.; et al. Gaussian 16, Revision B.01; Gaussian, Inc.: Wallingford, CT, USA, 2016.

32. Chemcraft Graphical Software for Visualization of Quantum Chemistry Computations. Available online: https://www. chemcraftprog.com (accessed on 12 November 2021).

33. Soler, J.M.; Artacho, E.; Gale, J.D.; García, A.; Junquera, J.; Ordejón, P.; Sanchez-Portal, D. The SIESTA method for ab initio order-N materials simulation. J. Phys. Cond. Matt. 2002, 14, 2745. [CrossRef]

34. García, A.; Papior, N.; Akhtar, A.; Artacho, E.; Blum, V.; Bosoni, E.; Brandimarte, P.; Brandbyge, M.; Cerdá, J.I.; Corsetti, F.; et al. SIESTA: Recent developments and applications. J. Chem. Phys. 2020, 152, 204108. [CrossRef]

35. Perdew, J.P.; Burke, K.; Ernzerhof, M. Generalized Gradient Approximation Made Simple. Phys. Rev. Lett. 1996, 77, 3865-3868. [CrossRef]

36. Troullier, N.; Matrins, J.L. Efficient Pseudopotentials for Plane-Wave Calculations. Phys. Rev. B. 1991, 43, 1993-2006. [CrossRef] [PubMed]

37. Solomon, M.M.; Umoren, S.A.; Quraishi, M.A.; Salman, M. Myristic acid based imidazoline derivative as effective corrosion inhibitor for steel in 15\% HCl medium. J. Colloid Interface Sci. 2019, 551, 47-60. [CrossRef] [PubMed]

38. Yadav, M.; Behera, D.; Kumar, S.; Sinha, R.R. Experimental and quantum chemical studies on the corosion inhibition performance of benzimidazole derivatives for mild steel in $\mathrm{HCl}$. Ind. Eng. Chem. Res. 2013, 52, 6318-6328. [CrossRef]

39. Yadav, M.; Behera, D.; Kumar, S. Experimental and theoretical investigation on adsorption and corrosion inhibition properties of imidazopyridine derivatives on mild steel in hydrochloric acid solution: Corrosion inhibition of mild steel in hydrochloric acid solution. Surf. Interface Anal. 2014, 46, 640-652. [CrossRef]

40. Zhang, H.H.; Chen, Y. Experimental and theoretical studies of benzaldehyde thiosemicarbazone derivatives as corrosion inhibitors for mild steel in acid media. J. Mol. Struct. 2019, 1177, 90-100. [CrossRef]

41. Ferreira, E.S.; Giacomelli, C.; Giacomelli, F.C.; Spinelli, A. Evaluation of the inhibitor effect of L-ascorbic acid on the corrosion of mild steel. Mater. Chem. Phys. 2004, 83, 129-134. [CrossRef]

42. Awad, M.I. Eco friendly corrosion inhibitors: Inhibitive action of quinine for corrosion of low carbon steel in $1 \mathrm{~m} \mathrm{HCl.} \mathrm{J.} \mathrm{Appl.}$ Electrochem. 2006, 36, 1163-1168. [CrossRef]

43. Luo, X.; Ci, C.; Li, J.; Lin, K.; Du, S.; Zhang, H.; Li, X.; Cheng, Y.F.; Zang, J.; Liu, Y. 4-Aminoazobenzene modified natural glucomannan as a green eco-friendly inhibitor for the mild steel in $0.5 \mathrm{M} \mathrm{HCl}$ solution. Corros. Sci. 2019, 151, 132-142. [CrossRef]

44. Wang, X.; Yang, H.; Wang, F. An investigation of benzimidazole derivative as corrosion inhibitor for mild steel in different concentration $\mathrm{HCl}$ solutions. Corros. Sci. 2011, 53, 113-121. [CrossRef]

45. Solomon, M.M.; Gerengi, H.; Kaya, T.; Kaya, E.; Umoren, S.A. Synergistic inhibition of St37 steel corrosion in $15 \% \mathrm{H}_{2} \mathrm{SO}_{4}$ solution by chitosan and iodide ion additives. Cellulose 2017, 24, 931-950. [CrossRef]

46. Solomon, M.M.; Gerengi, H.; Kaya, T.; Umoren, S.A. Performance evaluation of a chitosan/silver nanoparticles composite on St37 steel corrosion in a 15\% HCl solution. ACS Sustain. Chem. Eng. 2017, 5, 809-820. [CrossRef]

47. El-Haddad, M.A.M.; Radwan, A.B.; Sliem, M.H.; Hassan, W.M.I.; Abdullah, A.M. Highly efficient eco-friendly corrosion inhibitor for mild steel in 5M HCl at elevated temperatures: Experimental \& molecular dynamics study. Sci. Rep. 2019, 9, 3695. [PubMed]

48. Feng, R.; Beck, J.; Ziomek-Moroz, M.; Lvov, S.N. Electrochemical corrosion of ultra-high strength carbon steel in alkaline brines containing hydrogen sulfide. Electrochim. Acta 2016, 212, 998-1009. [CrossRef]

49. Yan, Y.; Li, W.; Cai, L.; Hou, B. Electrochemical and quantum chemical study of purines as corrosion inhibitors for mild steel in $1 \mathrm{M} \mathrm{HCl}$ solution. Electrochim. Acta 2008, 53, 5953-5960. [CrossRef]

50. El-Haddad, M.N. Chitosan as a green inhibitor for copper corrosion in acidic medium. Int. J. Biol. Macromol. 2013, 55, 142-149. [CrossRef] [PubMed]

51. Syed, J.A.; Tang, S.; Lu, H.; Meng, X. Water-soluble Polyaniline_Polyacrylic acid composites as efficient corrosion inhibitors for 316SS. Ind. Eng. Chem. Res. 2015, 54, 2950-2959. [CrossRef]

52. Hosseini, M.; Mertens, S.F.L.; Ghorbani, M.; Arshadi, M.R. Asymmetrical Schiff bases as inhibitors of mild steel corrosion in sulphuric acid media. Mater. Chem. Phys. 2003, 78, 800-808. [CrossRef]

53. Ashassi-Sorkhabi, H.; Shaabani, B.; Seifzadeh, D. Effect of some pyrimidinic Shciff bases on the corrosion of mild steel in hydrochloric acid solution. Electrochim. Acta 2005, 50, 3446-3452. [CrossRef]

54. Ghareba, S.; Omanovic, S. 12-Aminododecanoic acid as a corrosion inhibitor for carbon steel. Electrochim. Acta 2011, 56, 3890-3898. [CrossRef] 
55. Shenoy, V.V.; Venugopal, P.P.; Kumari, P.D.R.; Chakraborty, D. Effective inhibition of mild steel corrosion by 6-bromo-(2,4dimethoxyphenil)methylidene]imidazo[1,2-a]pyridine-2-carbohydrazide in $0.5 \mathrm{M} \mathrm{HCl}$ : Insights from experimental and computational study. J. Molecul. Struct. 2021, 1232, 130074. [CrossRef]

56. Fernandes, C.M.; Alvarez, L.X.; dos Santos, N.E.; Maldonado Barrios, A.C.; Ponzio, E.A. Green synthesis of 1-benzyl-4-phenyl-1h1,2,3-triazole, its application as corrosion inhibitor for mild steel in acidic medium and new approach of classical electrochemical analyses. Corros. Sci. 2019, 149, 185-194. [CrossRef]

57. Yadav, M.; Kumar, S.; Kumari, N.; Bahadur, I.; Ebenso, E.E. Experimental and theoretical studies on corrosion inhibition effect of synthesized benzothiazole derivatives on mild steel in 15\% $\mathrm{HCl}$ solution. Int. J. Electrochem. Sci. 2015, 10, 23.

58. Fares, M.M.; Maayta, A.K.; Al-Qudah, M.M. Pectin as promising green corrosion inhibitor of aluminum in hydrochloric acid solution. Corros. Sci. 2012, 60, 112-117. [CrossRef]

59. Farhadian, A.; Varfolomeev, M.A.; Shaabani, A.; Nasiri, S.; Vakhitov, I.; Zaripova, Y.F.; Yarkovoi, V.V.; Sukhov, A.V. Sulfonated chitosan as green and high cloud point kinetic methane hydrate and corrosion inhibitor: Experimental and theoretical studies. Carbohydr. Polym. 2020, 236, 116035. [CrossRef] [PubMed]

60. Luo, X.; Pan, X.; Yuan, S.; Du, S.; Zhang, C.; Liu, Y. Corrosion inhibition of mild steel in simulated seawater solution by a green eco-friendly mixture of glucomannan (GL) and bisquaternary ammonium salt (BQAS). Corros. Sci. 2017, 125, 139-151. [CrossRef]

61. Wysocka, J.; Cieslik, M.; Krakowiak, S.; Ryl, J. Carboxylic acids as efficient corrosion inhibitors of aluminium alloys in alkaline media. Electrochim. Acta 2018, 289, 175-192. [CrossRef]

62. Popova, A.; Sokolova, E.; Raicheva, S.; Christov, M. AC and DC study of the temperature effect on mild steel corrosion in acid media in the presence of benzimidazole derivatives. Corros. Sci. 2003, 45, 33-58. [CrossRef]

63. Ebenso, E.E.; Kabanda, M.M.; Murulana, L.C.; Singh, A.K.; Shukla, S.K. Electrochemical and quantum chemical investigation of some azine and thiazine dyes as potential corrosion inhibitors for mild steel in hydrochloric acid solution. Ind. Eng. Chem. Res. 2012, 51, 12940-12958. [CrossRef]

64. Bentiss, F.; Lebrini, M.; Lagrenée, M. Thermodynamic characterization of metal dissolution and inhibitor adsorption processes in mild steel/2,5- Bis(n-Thienyl)-1,3,4-thiadiazoles/hydrochloric acid system. Corros. Sci. 2005, 47, 2915-2931. [CrossRef]

65. Radwan, A.B.; Sliem, M.H.; Okonkwo, P.C.; Shibl, M.F.; Abdullah, A.M. Corrosion inhibition of API X120 steel in a highly aggressive medium using stearamidopropyl dimethylamine. J. Mol. Liq. 2017, 236, 220-231. [CrossRef]

66. Ansari, K.R.; Quraishi, M.A.; Singh, A. Schiff's base of pyridyl substituted triazoles as new and effective corrosion inhibitors for mild steel in hydrochloric acid solution. Corros. Sci. 2014, 79, 5-15. [CrossRef]

67. Obi-Egbedi, N.O.; Obot, I.B.; Eseola, A.O. Synthesis, characterization and corrosion inhibition efficiency of 2-(6-methylpyridin-2Y1)-1H-imidazo[4,5-f][1,10] phenanthroline on mild steel in sulphuric acid. Arab. J. Chem. 2014, 7, 197-207. [CrossRef]

68. Rbaa, M.; Lakhrissi, B. Novel oxazole and imidazole based on 8- hydroxyquinoline as a corrosion inhibition of mild steel in $\mathrm{HCl}$ solution: Insights from experimental and computational studies. Surf. Interfaces 2019, 15, 43-59. [CrossRef]

69. Jiang, L.; Qiang, Y.; Lei, Z.; Wang, J.; Qin, Z.; Xiang, B. Excellent corrosion inhibition performance of novel quinoline derivatives on mild steel in $\mathrm{HCl}$ media: Experimental and computational investigations. J. Mol. Liq. 2018, 255, 53-63. [CrossRef]

70. Govender, A.; Ferré, D.C.; Niemantsverdriet, J.W. The surface chemistry of water on Fe(100): A density functional theory study. Chem. Phys. Chem. 2012, 13, 1583. [CrossRef]

71. Freitas, R.R.Q.; Rivelino, R.; de Brito Mota, F.; de Castilho, C.M.C. Dissociative adsorption and aggregation of water on the Fe(100) surface: A dft study. J. Phys. Chem. C 2012, 116, 20306-20314. [CrossRef]

72. Jung, S.C.; Kang, M.H. Adsorption of a water molecule on Fe(100): Density functional calculations. Phys. Rev. B 2010, 81, 115460. [CrossRef]

73. Nazmutdinov, R.R.; Bronshtein, M.D.; Zinkicheva, T.T.; Glukhov, D.V. Modeling of Electron Transfer Across Electrochemical Interfaces: State-of-the Art and Challenges for Quantum and Computational Chemistry. Int. J. Quantum Chem. 2016, 116, 189-201. [CrossRef] 